Running head: Common dolphin distribution in the Eastern North Atlantic

\title{
Distribution and habitat modelling of common dolphins (Delphinus delphis) in the Eastern North Atlantic
}

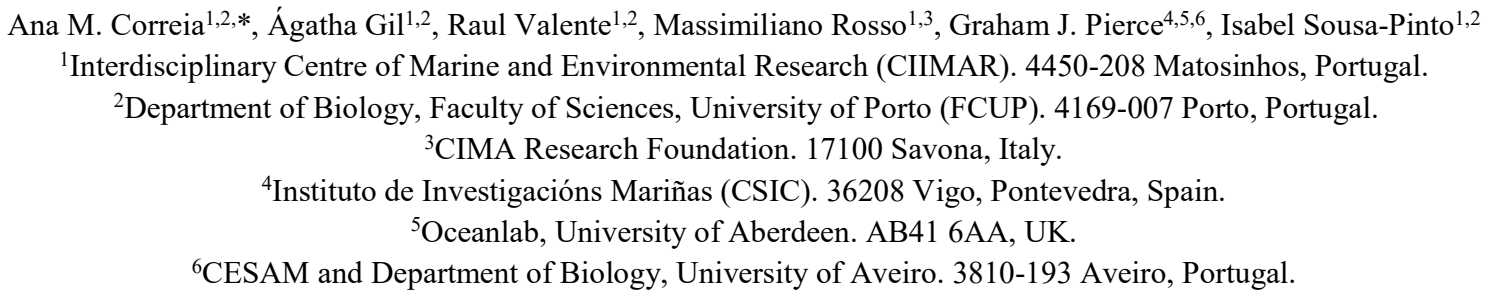

\section{Abstract}

The Eastern North Atlantic (ENA) has many highly productive areas where several species of cetaceans have been recorded, with the common dolphin (Delphinus delphis) being one of the most frequently sighted species. However, its spatial and temporal distribution in high seas is poorly known. The study presents the results from 5 years of cetacean monitoring in the ENA (2012-2016) aboard cargo ships that follow the routes from the Continental Portugal to the Macaronesian archipelagos and the Northwest Africa. Common dolphin was the most frequently sighted cetacean with 192 occurrences registered on effort and an overall encounter rate of 0.36 sightings / $100 \mathrm{nmi}$. The species was distributed in coastal and offshore waters, but absent from Canaries and Cape Verde islands. Statistical "habitat" models were developed to describe and explain the occurrence of sightings of the species: variables affecting detection of dolphins had a small impact and there were clear spatiotemporal distribution patterns, influenced to some degree by environmental variables. Predicted probability of occurrence was highest in coastal waters of continental Portugal and around the Azores. The models, combined with maps of distribution, were useful to identify important areas for the species, which could be the focus of future conservation efforts. Common dolphin presence was related to depth, distance to coast and seamounts, seabed slope, chlorophyll concentration, sea-surface temperature and sea level anomalies; the possible ecological significance of these relationships is explored.

Keywords: cetaceans; Macaronesia; high seas; spatial distribution; temporal distribution; ecological modelling 
36 The Eastern North Atlantic Ocean (ENA) includes the four archipelagos of the biogeographic region of Macaronesia: Azores, Madeira, Canaries and Cape Verde. The region has a complex topography including seamounts, hills, banks, abyssal platforms, canyons, and a rugged coastline along European and African continents. Moreover, it is characterized by dynamic oceanographic processes: strong coastal upwelling phenomena, formation of numerous eddies and fronts, and the presence of several Atlantic oceanic currents (Caldeira et al., 2002; Mason, 2009; Sala et al., 2013). This complexity and diversity of habitat conditions plays a major role in the distribution of primary production, and therefore, in the distribution of biomass across the trophic levels of the marine food chain. Cetacean distribution in space and time is generally considered to be shaped by environmental factors that condition prey availability at different spatial and temporal scales (for a review, see Redfern et al., 2006). Nonetheless, when looking at distribution based on observational data, it is necessary to account for factors affecting detectability in order to obtain reliable information (e.g., Pierce et al., 2010). These factors include the conditions of the platform of observation, survey design, state of the weather during the survey, distance to the sighted animal(s), species detected, size of the group, and, ultimately, the ability of the observer to detect and identify the species. In the ENA, at least 36 cetacean species have been recorded, both resident and migrating, in coastal and oceanic areas (e.g., Hazevoet \& Wenzel, 2000; Hazevoet et al., 2010; Weir et al., 2010; Carrillo et al., 2010; Alves et al., 2013; Hammond et al., 2013; Weir \& Pierce, 2013; Goetz et al., 2014; Silva et al., 2014; Berrow et al., 2015; Correia et al., 2015; Dinis et al., 2016; Djiba et al., 2015; Tobeña et al., 2016; Jungbult et al., 2017; Dinis et al., 2017; Alves et al., 2018; Alves et al., in press). All cetaceans in European Union (EU) waters receive protection under the Habitats Directive (Council Directive 92/43/EEC) and the Marine Strategy Framework Directive (MSFD, Directive 2008/56/EC). These directives demand both monitoring of cetacean population status 
(e.g. distribution, abundance) and enactment of conservation measures if population status is found to be unfavourable (see Santos \& Pierce, 2015, for a discussion of the application of the MSFD to cetaceans). Marine conservation in the ENA is also covered by several international organizations and agreements, including the International Council for the Exploration of the Sea (ICES, http://www.ices.dk/) the Convention for the Protection of the Marine Environment of the North-East Atlantic (OSPAR, http://www.ospar.org/), the Agreement on the Conservation of Small Cetaceans of the Baltic and North Seas (ASCOBANS) and the Agreement on the Conservation of Cetaceans of the Black Sea, Mediterranean Sea and contiguous Atlantic area (ACCOBAMS).

In the ENA, common dolphins (Delphinus delphis Linnaeus, 1758), are among the most frequently sighted cetacean species (Correia et al., 2015; Goetz et al., 2014; Silva et al., 2014; Hammond et al., 2013; Tobeña et al., 2016; Jungblut et al., 2017; Alves et al., 2018). Their distribution and habitat characteristics have been modelled in relation to geographic, physiographic, oceanographic and fishing-related variables, and several studies have identified well-defined habitat preferences related to the abundance of prey, for example productive areas (i.e., upwelling regions), with low to medium sea-surface temperatures, mostly coastal and shallow but often deeper waters, and/or areas that concentrate their preferred prey (e.g., Cañadas \& Hammond, 2008; Pierce et al., 2010; Moura et al., 2012; Goetz et al., 2014; Correia et al., 2015; Halicka, 2016; Tobeña et al., 2016). Their apparently patchy distribution suggests that common dolphins, although widely distributed, have a well-defined habitat and they may be dietary specialists in the sense of feeding on schooling fish (Moura et al., 2012; Marçalo et al., 2018). Common dolphins usually target high energy prey and/or locally abundant pelagic schooling fish and some of their prey have high commercial value, such as sardines, blue whiting, anchovy, sprat and horse mackerel, which often results in interactions of feeding dolphins with fisheries (e.g., Meynier et al., 2008; Santos et al., 2013; 2014; Marçalo et al., 
2018). In fact, negative impacts of fishery bycatch mortality and/or prey depletion due to overfishing of common dolphin prey have been widely reported. For example, in the Bay of Biscay, bycatch has been suggested to have reached unsustainable levels, inconsistent with the maintenance of common dolphin populations at a favourable status (Peltier et al., 2016). In the Mediterranean, overfishing is probably one of the causes for the estimated $50 \%$ decline in abundance of this species in the last 45 to 35 years, leading the Mediterranean sub-population of common dolphins to be listed as endangered in the IUCN Red List of Threatened Species (Piroddi et al., 2011; Cañadas \& Vázquez, 2017).

Common dolphin occurrence in coastal areas of the ENA (Weir et al., 2010; Moura et al., 2012; Hammond et al., 2013; Weir \& Pierce, 2013; Goetz et al., 2014; Djiba et al., 2015) and around the islands of Macaronesia (Hazevoet \& Wenzel, 2000; Carrillo et al., 2010; Silva et al., 2014; Halicka, 2016; Tobeña et al., 2016; Alves et al., 2018) is reasonably well reported, but in the high seas, where logistic constraints impede systematic surveys for cetacean monitoring, data are still lacking and spatial and temporal distribution of this species is poorly known (Correia et al., 2015; Jungbult et al., 2017). This baseline knowledge is fundamental to further assess the conservation status of the species and the impacts of human activities on its distribution, and to efficiently manage the status of common dolphins in the North Atlantic. In 2012, a monitoring project started collecting cetacean occurrence data in the ENA using cargo vessels as observation platforms of opportunity (OPOs) along routes from the Continental Portugal to the Macaronesian archipelagos and Northwest Africa (Correia et al., 2015). In the present study, the occurrences recorded in the surveys from 2012 to 2016 were used to analyse the spatial and temporal distribution of common dolphins. Four different models were developed to describe (i) the influence of detectability factors (observation effects model), (ii) dolphin distribution across space and time (spatiotemporal model), (iii) the influence of topographic and oceanographic features (environmental model), and (iv) a combination of all the above (final 
110 habitat model). We evaluate the usefulness of data collected from surveys on OPOs to develop

111 habitat models and to identify important areas for conservation across a wide area of ocean.

112 The results are expected to contribute to status evaluations by international organizations that

113 have responsibility or interest in the conservation of cetaceans, and to support legal instruments

114 for the management of the area.

115

116 MATERIALS AND METHODS

117 Study area

118 As part of the CETUS Project (http://www.cetusproject.com/), data on cetacean occurrence 119 were collected within the ENA. The study area included the coastal waters of Mainland Portugal 120 and of Northwest Africa, the waters in between (oceanic) and within the Macaronesian 121 archipelagos: the Azores and Madeira (Portugal) and the Canary (Spain) and Cape Verde 122 islands (Figure 1).

123 From 2012 to 2016, surveys for cetacean occurrence took place during 99 round-trips aboard 124 cargo ships belonging to TRANSINSULAR, a Portuguese maritime transport company. The 125 cargo ships were used as OPOs and each followed one of three different routes, all starting and 126 ending in Mainland Portugal, to the Azores, Madeira and Cape Verde respectively, with a total 127 of 15 ports visited, 10 of them routinely (Figure 1).

128 Most surveys were conducted during summer months (from July to October) with favourable 129 weather conditions for cetacean sampling, especially considering North Atlantic offshore areas 130 where sea conditions are generally rough during the rest of the year (Table 1).

\section{Data collection}

133 IN-SITU 
134 For each route, two observers were trained in use of survey protocols by the project team and

135 then boarded TRANSINSULAR cargo ships to visually monitor cetaceans throughout the trips.

136 Travel speed generally varied from 11 to 16 knots. Surveys were performed from sunrise to

137 sunset, whenever weather conditions were favourable (with sea state and wind speed up to 4, 138 on the Douglas and Beaufort scales respectively, and visibility over $1 \mathrm{~km}$ ) and the ship was 139 sailing outside the ports. Surveys stopped occasionally during periods when observers were not 140 allowed at the observation stands, i.e., during safety drills, cleaning of the deck or manoeuvres. 141 Observers stood in the navigation bridge and wings of the bridge, at an approximate height of 14220 metres above sea level (depending on the loading of the ship) and searched for cetacean 143 presence through 180 degrees, centred on the ship's heading, with and without binoculars 144 (magnification of $7 \times 50 \mathrm{~mm}$, with scale and compass). When cetaceans were sighted, the 145 species was identified and number of individuals recorded. When it was not possible to 146 determine the exact number of individuals, a minimum and maximum number of animals was 147 recorded, as well as the most probable number of individuals according to the observer's 148 perception (best estimate). Besides cetacean occurrence, data on the presence of other top 149 predators (e.g., turtles, sharks, tuna), as well as information on weather conditions and marine 150 traffic, were collected. For more details on sampling protocol, see Correia et al. (2015). Since 151 the present paper is focused on common dolphins (Delphinus delphis Linnaeus, 1758), results 152 for other species will be presented elsewhere.

154 REMOTE SENSING

155 For the statistical habitat modelling, in addition to weather conditions and spatiotemporal 156 variables needed for both observational and spatiotemporal models, habitat variables were 157 derived from satellite data at several temporal and spatial scales (see Table 2). Slope was 158 derived from bathymetry data. For distance to seamounts, topographic features classified as 
seamounts, banks, hills, ridges and rises in GEBCO (GEBCO 2017) were delimited, using

160 contour lines created every $50 \mathrm{~m}$, and defining a polygon from the outermost closed contour line

161 around the geographic location of the top of the features. Then, the distance from the base of

162 the seamounts and from the coastline (distance to coast) to the sightings was calculated. Both

163 slope and distances were computed using ArcGIS 10.5 (ESRI 2016).

164 For dynamic variables, satellite data were used. Chlorophyll-a and sea-surface temperature are 165 ocean products derived from the satellite MODIS - Aqua Mapped data from NASA (NASA, 166 2017). The algorithms return the near-surface concentration of chlorophyll-a (from in situ 167 remote sensing reflectance) and temperature (from measured radiances). Both variables were 168 extracted at two different temporal and spatial scales. Chlorophyll-a was extracted for the 169 calendar month and week in which the sightings occurred but also with four different time lags 170 (one and two weeks and months of lag). For altimetry, the mean sea level anomalies were 171 obtained from Ssalto/Duacs multimission altimeter products provided by AVISO (AVISO, 172 2017). The sea level anomalies are sea-surface heights computed with respect to a twenty-year 173 mean profile (1993-2012). When assembling data for sea level anomalies, delayed products 174 were available only until $5^{\text {th }}$ of May, 2016 and, as a consequence, near-real time products were 175 used for July-October, 2016. Near-real time final products become available six days after the 176 date of measurement, but are less precise than delayed products, which become available 177 around two months after collection, having been re-analysed and re-processed (AVISO, 2017). 178 For this variable, weekly and monthly resolutions were computed by averaging daily products.

\section{Data analysis}

181 Total and on effort sightings of common dolphins per season of survey and route were computed, as well as the survey effort. On effort sightings are those recorded during survey

183 effort, while total number includes off effort sightings recorded opportunistically. The group 
184 size (minimum, maximum, mean and standard deviation values) was accessed from the

185 recorded best estimate for the number of individuals in the group (Table 1). For the remaining analyses, an individual sighting was used as the sampling unit, regardless of the group size.

187 Encounter rates were computed as the total number of sightings on effort per 100 nautical miles 188 (nmi) surveyed, for each season and route. Then, the spatial and temporal distributions of 189 common dolphin occurrences were analysed for the entire study area (considering data from 190 the three routes), computing geographical positions and monthly variation of sightings, survey 191 effort and encounter rate.

192 Statistical modelling was performed using Generalized Additive Models (GAMs), which have 193 been widely used to describe cetacean distribution and habitat characteristics. An approach 194 based on used/available habitat was chosen (Pearce \& Boyce, 2006; Elith \& Leathwick, 2009; 195 Correia et al., 2015), with used (common dolphin sightings on effort) and available (survey route) habitat points combined to generate a binary $(1,0)$ response variable. The set of available points was created as in Correia et al. (2015), through the creation of equidistant points (every $2.5 \mathrm{nmi}$ ) along all effort tracks. Using this methodology guarantees that areas that had a higher survey effort are given more points of available habitat, hence, survey effort is being taken into 200 account in the models. The values of the variables to use as predictors in the modelling process were extracted from the set of used and available points (Table 2). For oceanographic variables,

202 the pack of tools for ArcGIS, Marine Geospatial Ecology Tools (MGET) (Roberts et al., 2010) 203 was used.

204 Prior to modelling, Pearson correlation between explanatory variables was computed to avoid 205 using highly correlated variables in the same model (threshold of 0.75) (after Marubini et al., 206 2009). Distance to coast and depth were the only pair of variables highly positively correlated.

207 Since both were of interest, a GAM model was fitted, with depth as predictor and distance to 208 coast as response variable, and both depth and the residuals of this model were used as 
predictors in the common dolphin models (see Smith et al., 2011). Moreover, multiple

210 correlation among explanatory variables was assessed through the Variance Inflation Factor

211 (VIF, with a threshold of 3) (Zuur et al., 2010). After replacing distance to coast by the residual

212 distance as described above, all remaining variables had VIF values $<3$ and no additional

213 variables were removed.

214 A binomial distribution was assumed for the response variable and a maximum of four splines

215 was used (k-fold set to 4) to limit the complexity of smoothers describing effects of explanatory

216 variables. Model fitting mainly involved backward selection, starting from an oversaturated

217 model (Quian, 2009; Viddi et al., 2010; Correia et al., 2015). However, forward selection was

218 undertaken when choosing between the different scales of the oceanographic variables (and

219 different time lags for chlorophyll). Interactions between spatial and temporal variables were

220 also explored in the fitting process to account for main and interaction effects: interaction

221 between latitude with longitude and between year with day of the year. This was done by

222 including these pairs of variables in two dimensional smoothers and visualising the results as

223 surface plots (in this case, the k-fold was set to 16 as to account for the interaction effect, i.e.,

224 four times four).

225 Following Correia et al. (2015), and to account for varying dolphin group size, a weight 226 parameter was included in the models, corresponding to the best estimate of animals sighted

227 for each observation. Given the wide range of group size and high uncertainty of the 228 estimations, weights were attributed in categories: a small group - from one to five animals 229 (weight $=1$ ); a medium group - from six to 20 animals (weight $=2$ ); a large group - more than 23020 animals (weight $=3$ ). A weight of 1 was set for points of available habitat.

231 Best models were selected by using the Akaike Information Criterion (AIC) as a measure of 232 goodness of fit, choosing the model with the lowest AIC value at each step of the model fitting 233 process, i.e. comparing otherwise identical models with or without a specific explanatory 
234 variable. If the difference in AIC values between two models was less than 2, a Chi-squared

235 test was applied. Whenever differences between AIC values were not statistically significant

236 (based on $\delta \mathrm{AIC}>2$ or the chi-square test result), the simplest model was maintained (following

237 the principle of parsimony, e.g. Burnham \& Anderson, 2002). Finally, at the end of the

238 modelling process, the models were evaluated by creating two random subsets of data: fitting

239 and evaluating sets ( $75 \%$ and $25 \%$ of the data, respectively). Prediction power of the models

240 was determined using the Area Under the Curve (AUC) metric of the Receiving Operator

241 Characteristic (ROC) curve (Beck \& Shultz, 1986).

242 Four different models were developed, three of these to specifically evaluate, respectively (i)

243 variables affecting cetacean detection (observation effects model), (ii) spatiotemporal variation

244 (spatiotemporal model) and (iii) habitat preferences (environmental model). Model iv, the final

245 habitat model, used a combination of all the variables tested (Table 2) and was then used to

246 predict probabilities of common dolphin occurrence at the set of used/available points along the

247 routes. Prediction was done using all the original data values for explanatory variables.

248 Finally, predicted probabilities of dolphin occurrence at the points were represented in a map.

249 Maps were created in ArcGIS 10.5 (ESRI 2016) using a Mercator projection (EPSG: 4326), 250 graphs in Microsoft Excel 2016 and statistical modelling was carried out using R (R 251 Development Core Team 2012) with R Studio.

253 RESULTS

\section{Survey effort}

255 Most of the survey effort was during summer months, from July to October. A total of 2073 256 sightings was collected and 26 species identified (at least to genus), with 17 species occurring 257 along the Madeira route, 11 along the Azores route and 25 along the Cape Verde route. Sighted 258 species included baleen whales, toothed whales, dolphins and porpoises, with most sightings 
being of dolphin species. With a total of $25475 \mathrm{nmi}$ surveyed, the route to Madeira was the

260 most sampled, being surveyed since 2012 (Table 1). Survey effort was heterogeneous across

261 the sampled transect with some gaps due to periods of bad weather conditions as well as areas

262 crossed during night time (Figure 2).

263

264 Spatiotemporal distribution of common dolphins

265 Common dolphin (Delphinus delphis Linnaeus, 1758) was the most frequently sighted species 266 (283 sightings, approximately $14 \%$ of the all species total), present over a wide latitudinal 267 range, but mostly sighted in northern latitudes within the sampled area, with fewer occurrences 268 south of Madeira island (Table 1 and Figure 2).

269 There were 192 on effort sightings of common dolphins, giving an overall encounter rate of 2700.36 sightings / $100 \mathrm{nmi}$ (Table 1). Common dolphin groups varied in size between one and 2712500 animals and encounter rates (by route and by year) ranged from 0.28 sightings / $100 \mathrm{nmi}$ 272 (2012 along Madeira route and 2015 on the Cape Verde route) to 0.54 sightings / $100 \mathrm{nmi}$ (2016 273 on the Azores route) (Table 1). The largest group, of 2500 animals, was recorded off Dakar, in 2742015 (Figure 2).

275 The highest monthly number of common dolphin sightings on effort (20) was in August 2016, 276 while the highest monthly encounter rate (0.73 sightings / $100 \mathrm{nmi})$ was recorded in October, 277 2013, with 10 on effort sightings over $1370 \mathrm{nmi}$ surveyed. No common dolphin sightings were 278 registered in the months with the lowest survey effort (February, March and December, 2016) 279 (Figure 3).

281 Modelling

282 Of the three initial models, the model fitted for observation effects had the lowest deviance 283 explained (4.11\%) and AUC (0.689), while the spatiotemporal model had a slightly higher 
284 deviance explained (16.5\%) than the environmental model $(15.5 \%)$. The final habitat model

285 had the highest deviance explained (22.3\%) and included variables from all the three models 286 above (Table 3).

287 All the three variables tested, namely sea state, wind state and visibility, contributed to the 288 observation effects model. Sea state had a positive effect over the range Douglas 2 to 4, 289 visibility had an overall positive influence, albeit with a negative effect apparent at intermediate 290 visibilities (range 7 to 8), and wind-state had a negative influence over the range Beaufort 1 to 2913 (Figure 4).

292 The spatiotemporal model included latitude $\times$ longitude and year $\times$ day effects (i.e. main effects 293 and interactions). There were positive effects at several different geographical locations within 294 the surveyed area: northern latitudes with eastern longitudes, corresponding to the proximities 295 of the continental Portugal; northern latitudes with western longitudes, corresponding to Azores 296 region; and a smaller peak at southern latitudes with eastern longitudes, along the African coast.

297 As for the temporal variables, the surface of the year $\times$ day of year plot varies along the day of 298 year axis with the same pattern seen across all years. A peak is observed in the beginning of the 299 survey season (July), sightings rate decreasing thereafter and with a smaller peak at the end 300 (October) (Figure 5).

301 The environmental model included seven environmental variables: depth, residuals from the 302 model of distance to coast versus depth, slope, distance to seamounts, chlorophyll 303 concentration, sea surface temperature and mean sea level anomaly. Depth had an almost linear 304 negative correlation with common dolphin occurrence, i.e. there was a lower probability of 305 sightings over deeper waters. As for the residuals from the model of distance to coast versus depth, GAM results indicate that, for a given depth, there is a positive influence of proximity 307 to coastal areas. In relation to seabed slope, there was a peak in sightings probability at 308 approximately five degrees of slope, with predicted dolphin presence then decreasing over 
steeper slopes. Distance to seamounts had a negative effect up to $300 \mathrm{~km}$ and then a positive

310 effect towards areas most distant from seamounts. Both chlorophyll and sea-surface 311 temperature had a broadly negative effect, while for mean sea level anomaly there was a 312 negative correlation between $0.07 \mathrm{~cm}$ and $0.15 \mathrm{~cm}$ but also a probable positive correlation at 313 higher anomaly values (where, however, the confidence interval is wide). While sea-surface 314 temperature and mean sea level anomalies had the highest explanatory power at the finest 315 spatial and temporal resolutions (8-day for both and $4 \mathrm{~km}$ for sea-surface temperature), 316 chlorophyll presented a strong relationship with sightings at the lowest resolution, both spatially 317 and temporally, and with no lags (Figure 6).

318 The final habitat model, where all the variables were tested during the fitting process, included 319 ten variables with two interactions among variables, namely the spatial (latitude with longitude) 320 and temporal (day of the year with year of survey) variables. By introducing the dynamic 321 variables, chlorophyll and sea-surface temperature, the total number of observations decreases 322 (from 192 to 165), and consequently the number of available habitat points also decreases, as 323 these variables were collected from satellite data and presented several data gaps (Table 3). 324 While combining all predictors, the effects illustrated by the smooth curves for the variables 325 included remain similar to their forms in the previous models. Dolphin presence was negatively 326 and linearly related to chlorophyll concentration. The relationship between sightings and depth 327 was approximately linear and also negative. The other variables had non-linear fits, with more 328 complex relationships with the response variable. In general, probability of common dolphin 329 detection was highest with low wind speed (low values on the Beaufort scale) and very good 330 visibility. Common dolphin occurrence was more likely in areas further than $300 \mathrm{~km}$ from 331 seamounts and at locations of intermediate and high positive sea level anomalies. Occurrence 332 varied spatially (with peaks in Portuguese and African coastal areas and Azorean islands) with 
333 a relatively consistent seasonal pattern over the years of the survey (increase in the beginning

334 of the season and small peak at the end) (Figure 7).

335 When mapping probability of occurrence predicted by the final GAM habitat model, at the set

336 of available and used points along the route, two main areas stood out as having the highest 337 values for predicted probability of common dolphin occurrence ( $28 \%$ to $47 \%)$ : coastal 338 continental Portugal and the Azores archipelago. The areas of Madeira island and in the open 339 ocean close to continental Portugal and in front of the Nouadhibou port in Mauritania had 340 intermediate probabilities of dolphin occurrence (10\% to $28 \%$ ) (Figure 8 ).

\section{DISCUSSION}

343 This study presents the results from a 5-year data set on common dolphin (Delphinus delphis 344 Linnaeus, 1758) occurrence from systematic surveys for cetacean monitoring in the ENA, with 345 a great amount of effort carried out along a wide latitudinal range of about $30^{\circ}$ latitude, mostly 346 in poorly surveyed areas such as the high seas. Survey effort was concentrated in summer 347 months, which is very common in marine surveys dependent on weather conditions (Redfern 348 et al., 2006; Kaschner et al., 2010; Kaschner et al., 2012). Hence, results here presented reflect 349 common dolphin distribution mainly for this period and few conclusions can be drawn for the 350 remaining months of the year.

351 Common dolphin was the most frequently encountered species, accounting for $14 \%$ of the 352 sightings across 26 species. This species has been reported as being among the most abundant 353 in the area, however most studies present data mainly for coastal areas and islands (Goetz et 354 al., 2014; Silva et al., 2014; Hammond et al., 2013; Tobeña et al., 2016; Alves et al., 2018). On 355 the contrary, the present study sampled mostly areas in the high seas. The biggest group of 356 common dolphin, comprising approximately 2500 individuals, was recorded off Dakar in 2015.

357 Large pods of dolphins have been registered previously in the coastal areas of Northwest Africa 
358 (Bowman Bishaw Gorham, 2003; Camphuysen et al., 2012; Weir et al., 2014; Djiba et al., 359 2015). The group size was highly variable, which is consistent with published results for coastal 360 areas (e.g., Djiba et al., 2015), islands (e.g., Alves et al., 2018) and high seas (e.g., Correia et 361 al., 2015). Group size has been correlated with the water depth and, in the case of common 362 dolphins, larger pods, frequently with calves, often occur closer to the coast (Cañadas \& 363 Hammond, 2008).

364 Spatially, common dolphin occurrences were most frequently registered over the shelf of continental Portugal and around the Azores and Madeira islands. There were also sightings along the entire Madeira route, which may be a consequence of higher survey effort but also an 367 effect of the complex topography (Schlacher et al., 2010; Correia et al., 2015). Along the routes 368 to the Azores and Cape Verde, there were areas with a total absence of sightings. No sightings 369 of common dolphin were recorded in the Canaries and Cape Verde archipelagos. Our results 370 for the Canaries are consistent with those from Carrillo et al. (2010) who reported the seasonal 371 presence of common dolphins in the Canary Islands from December to May, the species being 372 absent from June to November.

373 The year to year variation in common dolphin encounter rates did not present any clear pattern, 374 which may relate to the spatial heterogeneity of survey effort. In fact, encounter rates peaked 375 in different seasons in different years. In 2016, no encounters were registered in the months of 376 February, March and December, but during these months only the route to Cape Verde was 377 monitored and effort was very low.

378 Putative explanatory variables were chosen for the modelling process according to the effects 379 they may have on the presence of common dolphins (based on the literature) but also reflecting 380 availability. Observation effects were modelled to test whether the weather conditions likely to 381 affect detection of dolphins strongly influenced the models. While detectability factors are not 382 always included or tested in habitat modelling, their inclusion should provide more reliable 
results (Pierce et al., 2010). While the variables tested did significantly affect the probability of

384 seeing common dolphins, the observational effects model (as might be expected) had the lowest 385 deviance explained of all the models (4.11\%). Contrary to what was expected, sea state was positively correlated with common dolphin occurrence with probability of sighting increasing with higher wave height, at least in the range Douglas 2 to 3 . This is probably due to the fact that common dolphins tend to surf down the leading edge of waves (possibly to save energy) and thus may be visible at the surface for longer if the waves are higher and wider. Nonetheless, this variable was then excluded from the final habitat model as it did not significantly affect common dolphin presence when considering the effects of the remaining predictors. Although 392 weather conditions affect the detection of cetaceans which in turn influences model results 393 (Pierce et al. 2010), in this case, observation effects had a very low explanatory power; hence 394 deviance explained in the final model is mainly related with the other predictors.

395 The spatiotemporal and environmental models had similar values of deviance explained, 16.5\% 396 and $15.5 \%$ respectively, likely to a large extent capturing the same variation since the best final 397 model explained only $22.3 \%$ of deviance. Some habitat variables were excluded from the best 398 final model while geographic location and temporal variables (days and years) were retained, 399 presumably thus accounting for the effects of other habitat variables not being considered (Elith 400 \& Leathwick, 2009; Pirotta et al., 2011; Spyrakos et al., 2011; Correia et al., 2015). Over three401 quarters of the variation in presence remains unexplained. In part this may be because relevant 402 habitat variables were not included but it is also likely that many of the observed animals were 403 travelling through less-preferred habitat.

404 In general, common dolphin probability of occurrence was higher in continental regions 405 (continental Portugal and African coast) and in the area of Azores. As for seasonality, there 406 seems to be a higher probability of occurrence at the beginning and the end of the survey season 407 (July and October). However, this temporal trend should be interpreted with caution as there 
was substantial temporal heterogeneity in survey effort, which may be a source of noise in the

409 analysis. If occurrence really is lower in the middle of the survey season, the question is whether 410 this indicates animals moving out of the survey area (or at least away from the survey trackline)

411 or a change in behaviour (e.g. aggregation, surfacing or response to boats). Nevertheless, the 412 surface in the temporal perspective plot shows that common dolphin presence varies through 413 the days of the year, with a pattern that remains relatively constant between years, pointing to 414 a seasonal pattern. Seasonality of common dolphin occurrence in the different archipelagos of 415 Macaronesia has been reported, in general, with higher abundances in cold months and a 416 negative tendency during the summer months: in Madeira (Halicka, 2016; Alves et al., 2018), 417 Azores (Silva et al., 2014; Tobeña et al., 2016) and in Canary Islands (Carrillo et al., 2010). 418 The decrease of abundance in summer months is consistent with results presented here.

419 For the environmental variables, different spatial and temporal scales were tested. It has been 420 shown that spatial and temporal scales affect model results and it is important to understand at

421 which scale the impacts of the variable are significant for the presence of the species (Fernandez 422 et al., 2017; 2018; González et al., 2018). Some of the variables included in the environmental 423 model were dropped from the final combined habitat model during the fitting process. This 424 probably reflects the fact that their effects are already explained by spatial and temporal 425 variables and thus does not mean they are unimportant. However, depth, distance to seamounts, 426 chlorophyll and sea level anomalies remained statistically significant in the final habitat model, 427 increasing the overall deviance explained and having a clear influence in the spatiotemporal 428 patterns.

429 Depth had an almost linear negative correlation with common dolphin presence. In the 430 environmental model, the residual effect of the distance to coast (after taking depth into 431 account) is negative, i.e. there is a preference for coastal waters. However, in the final habitat 432 model this effect is probably being captured by longitude. A preference for shallower and 
coastal waters has been reported for common dolphins in several different studies, a result most

434 likely due to the distribution of their preferred prey (Cañadas \& Hammond, 2008; Meynier et al., 2008; Stockin et al., 2008; Moura et al., 2012; Santos et al., 2013; 2014; Correia et al., 2015; Alves et al., 2018), although strictly speaking we cannot prove whether diet choice follows from habitat choice or vice versa. Another suggestion for the coastal distribution is the 438 presence of calves within the group (Cañadas \& Hammond, 2008; Stockin et al., 2008; Alves 439 et al., 2018). However, since this information was not collected in the present study, such a 440 relationship could not be investigated. Most survey effort in previous studies was coastal, so 441 the preferences of common dolphins could be reflecting sampled rather than preferred areas; in 442 the present study, this is not the case as most effort was in deeper, offshore waters.

443 Although seamounts have a positive effect in cetacean presence, especially in the high seas 444 where these structures act as oases of productivity in rather oligotrophic waters (Schlacher et $445 a l ., 2010)$, they did not seem to strongly influence common dolphin distribution. In fact, the 446 model results indicate the highest probability of occurrences furthest from the seamounts (more 447 than $300 \mathrm{~km}$ distance), which probably relates to the preference for coastal areas that are located 448 furthest from the seamounts.

449 Sea surface temperature acts as a good indicator of upwelling phenomena that are characterized 450 by the cold productive waters at the surface (Caldeira et al., 2002; Mason, 2009). In the 451 environmental model, an increase in sea surface temperature negatively affects common 452 dolphin presence, pointing to a preference for colder waters. The ENA is characterized by 453 strong coastal upwellings (Caldeira et al., 2002; Mason, 2009), that are characterized by colder 454 surface waters. This may explain the apparent preference for colder waters. The preference of 455 common dolphins for more productive areas associated with strong upwellings has been 456 reported before, as well as a tendency to prefer colder waters rather than warmer (sub-) tropical 457 waters (Cañadas \& Hammond, 2008; Stockin et al., 2008; Jefferson et al., 2009; Moura et al., 
2012; Halicka, 2016). However, when including all the other variables, the sea-surface

459 temperature does not significantly affect common dolphin distribution. This is probably

460 because the sea-surface temperature pattern in the area is related to latitude, with a decrease of

461 temperature from north to south, and distance to coast, with an abrupt decrease of temperature

462 during coastal upwellings.

463 The surveyed area is highly dynamic and habitat is influenced by several current systems

464 (Caldeira et al., 2002; Mason, 2009). The sea level anomalies reflect this dynamism, probably

465 not fully captured by spatial and temporal variables, and are related to productivity, being

466 affected by upwelling and downwelling phenomena and currents that aggregate or disperse prey

467 (Davis et al., 2002; Baird et al., 2011; Robinson, 2011). Two different temporal scales were

468 tested for the altimetry data, with the 8-day resolution leading to the model with highest

469 deviance explained. The fit indicates that common dolphin presence is more strongly affected

470 at a weekly than a monthly scale, probably due to the high dynamism in the area. This also

471 means that models would probably benefit from a better spatial resolution for altimetry, as the

472 one available is rather low ( 0.25 degrees, approximately $28 \mathrm{~km})$. In the study area, there is a

473 complex relationship between sea level anomalies and common dolphin presence, with a

474 decrease in probability of occurrence at intermediate positive anomalies and an increase at more

475 highly positive anomalies. This complex relationship may however indicate overfitting in the

476 model.

477 In the case of the chlorophyll concentration, different temporal lags were also tested, besides

478 the different spatial and temporal scales. The rationale is that chlorophyll is a proxy for 479 productivity and there is a temporal) lag (and possibly also spatial displacement) between 480 chlorophyll blooms and high abundance of common dolphin prey (Frederiksen et al., 2006; 481 Grémillet et al., 2008). Nonetheless, and contrary to the result for sea-surface temperature and 482 altimetry, the chlorophyll had the highest explanatory power at the lowest resolution, both 
spatially and temporally, and with zero lag. Chlorophyll negatively affected common dolphin

484 presence, contrary to what was expected (Cañadas \& Hammond, 2008; Moura et al., 2012;

485 Halicka, 2016; Tobeña et al., 2016). However, the influence of chlorophyll reflected in these results has to be interpreted with caution, partly due to the wide confidence limits around the fitted line but mostly because, as with all the explanatory variables, we are describing partial 488 effects, once effects of all other variables in the model have been taken into account. Also, most 489 of the survey is in the high seas, comprising mostly oligotrophic areas, with a low representation of effort in coastal areas which leads to a highly heterogeneous distribution of records within 491 the range of chlorophyll values. In previous studies that reported positive relationships between 492 chlorophyll and common dolphin presence, survey effort was mostly concentrated in coastal 493 areas, thus providing a wider range of chlorophyll values, making this a good proxy for 494 productivity (Cañadas \& Hammond, 2008; Moura et al., 2012; Halicka, 2016; Tobeña et al., 495 2016). However, in this study, a wide range of depth values was sampled while the surveys passed through mainly oligotrophic waters which resulted in a small range of chlorophyll values 497 sampled, hence depth being a better proxy for areas of upwelling (i.e., more productive areas). 498 Moreover, timings of the chlorophyll blooms vary across the area and common dolphin 499 distribution may not be affected by production at certain times of the year, or in certain areas 500 where other factors are more important. Hence, although the inclusion of chlorophyll 501 concentration improves the overall model result, it is not very useful for the ecological 502 interpretation of the distribution when working over such a wide area. To test the effect of 503 chlorophyll, models would probably perform better when working in narrower areas and with 504 a more homogeneous effort across the range of available chlorophyll values.

505 Maps of the predicted probabilities along the routes illustrate the model results, highlighting 506 the areas where sighting probabilities reach the highest values: coastal continental Portugal and 
507 the Azores archipelago, with slightly lower probabilities in Madeira and in the open-ocean areas

508 close to continental Portugal and in front of Nouadhibou port in Mauritania.

509 This study shows that common dolphins have core areas of occurrence, thus supporting the idea

510 that the species is more of an ecological specialist than a generalist (Moura et al., 2012; Marçalo

511 et al., 2018). The explanatory power of the models developed was relatively low (under 25\%)

512 and, in fact, we have to be realistic about how much we can expect a model to explain about

513 the distribution of a highly mobile species in such a wide area. Moreover, we are grouping 514 animals that are potentially using the area for different purposes (e.g., foraging or travelling).

515 Also, we have to be aware that cetaceans spend a great amount of time underwater so that, with 516 visual observational data, we are only getting a sample of their occurrence. Finally, we do not 517 have a complete knowledge about all the environmental variables that may influence 518 distribution and we cannot assume that cetaceans occurring in the area have perfect knowledge 519 about prey distribution and its variation across seasons and years, so models based on resource 520 selection functions will only tell us where animals are more likely to be, based on an incomplete 521 knowledge of all the predictors involved. Nevertheless, all models performed considerably 522 better than a random model $(\mathrm{AUC}>0.5)$ and provide new information on common dolphin 523 preferences in the area between the months of July and October, especially in the high seas 524 region. Spatial and temporal predictors had a slightly stronger influence than environmental 525 variables on common dolphin distribution. In this wide study area, with surveys occurring over 526 five years and with heterogeneous effort, it is likely that the spatial pattern and the seasonality 527 of common occurrence are linked to different habitat characteristics, also reflecting the effects 528 of several environmental variables. However further work would be needed to determine which 529 environmental variables are involved. Hence, in this context, the models, combined with the 530 spatial and temporal distribution of occurrences, are more successful in identifying important 
531 areas of conservation than explaining the ecological rationale for the common dolphin 532 distribution.

533 This study has several limitations, mostly related with effort heterogeneity, both temporally and

534 spatially: surveys evidently depend on the company's schedule and the surveys along the three 535 routes began in different years, with the Madeira route starting first (2012), therefore having a 536 higher survey effort than the other two transects. Such differences in effort along line-transects 537 are an almost unavoidable disadvantage of using OPOs (Kiszka et al., 2007; MacLeod et al., 538 2008; Moura et al., 2012; Correia et al., 2015).

539 Nonetheless, this work shows that the use of OPOs to systematically monitor cetaceans provides 540 important data to fill data gaps in space and time, especially in areas that are logistically 541 challenging for dedicated surveys and where baseline knowledge is needed, i.e. the high seas.

542 It constitutes an important contribution to the knowledge of common dolphin distribution in the 543 ENA, with records in poorly surveyed areas and insights in habitat preferences based on a 5544 year dataset of systematic surveys and a great amount of effort. However, more surveys are still 545 needed to fill knowledge gaps, mainly in relation to seasonal variation, as results here presented 546 mainly reflect temporal variation from July and October, failing to provide a year-round 547 distribution of common dolphins in the area.

ACKNOWLEDGEMENTS

550 We thank the contribution and dedication of all the volunteers during the monitoring campaigns.

551 We are extremely grateful to TRANSINSULAR, the cargo ship company that provided all the 552 logistic support, and to the ships crews for their hospitality. We thank the reviewers for their 553 comments and suggestions. 
556 This study was conducted within a PhD program from the Faculty of Sciences of the University

557 of Porto, Portugal, hosted by the Centre of Marine and Environmental Research (CIIMAR -

558 Porto, Portugal) and funded by the Portuguese national funding agency for science, research

559 and technology (FCT) under the grant SFRH/BD/100606/2014. CETUS Project is led by 560 CIIMAR | University of Porto in partnership with the cargo ship company TRANSINSULAR |

561 ETE Group.

562

563

REFERENCES

564 AVISO

(2017).

Sea-surface

Height

Products.

565 https://www.aviso.altimetry.fr/en/data/products/sea-surface-height-products/global/msla-

566 h.html (accessed September 2017).

567 Alves F., Ferreira R., Fernandes M., Halicka Z., Dias L. and Dinis A. (2018). Analysis of

568 occurrence patterns and biological factors of cetaceans based on long-term and fine-scale data

569 from platforms of opportunity: Madeira Island as a case study. Marine Ecology. doi:

$570 \quad 10.1111 /$ maec.12499.

571 Alves F., A. Alessandrini, A. Servidio, A. S. Mendonça, K. L. Hartman, R. Prieto, S.

572 Berrow, et al. (in press). Complex biogeographical patterns support an ecological connectivity

573 network of a large marine predator in the north-east Atlantic. Diversity and Distributions. doi:

$574 \quad 10.1111 /$ ddi.12848.

575 Alves F., S. Quérouil, A. Dinis, C. Nicolau, C. Ribeiro, L. Freitas, M. Kaufmann, C.

576 Fortuna (2013). Population structure of short-finned pilot whales in the oceanic archipelago of

577 Madeira based on photo-identification and genetic analyses: implications for conservation.

578 Aquatic Conservation: Marine and Freshwater Ecosystems 23(5):758-776.

579 Baird R.W., Schorr G.S., Webster D.L., Mahaffy S.D., McSweeney D.J., Hanson M.B. and

580 Andrews R.D. (2011). Open-ocean movements of a satellite-tagged Blainville's beaked whale 
581 (Mesoplodon densirostris): evidence for an offshore population in Hawaii? Aquatic Mammals $582 \quad 37(4): 506-511$.

583 Beck J.R. and Shultz E.K. (1986). The use of relative operating characteristic (ROC) curves 584 in test performance evaluation. Archives of Pathology \& Laboratory Medicine 110:13-20.

585 Berrow S., Suárez P.L., Jann B., O’Brien J., Ryan C., Varela J. and Hazevoet C.J. (2015). 586 Recent and noteworthy records of Cetacea from the Cape Verde Islands. Zoologia 587 Caboverdiana 5(2):111-115.

588 Bowman Bishaw Gorham. Chinguetti Development Project (2003) Seabird and Cetacean 589 Surveys in the Vicinity of the Chinguetti Oil Field, Offshore Mauritania. Woodside Australian 590 Energy, 66pp.

591 Burnham K.P. and Anderson D.R. (2002). Model Selection and Multimodel Inference: a 592 Practical Information Theoretic Approach. Springer Verlag: New York, USA.

593 Caldeira R.M.A., Groom S., Miller P., Pilgrim D. and Nezlin NP (2002). Sea-surface 594 signatures of the Island mass effect phenomena around Madeira Island, Northeast Atlantic. 595 Remote Sensing of Environment 80:336-360.

596 Camphuysen C.J., van Spanje T.M. and Verdaat H. (2012) Ship based seabird and marine 597 mammal surveys off Mauritania, Nov-Dez 2012 - cruise report. Mauritanian Institute for 598 oceanographic research and fisheries - IMROP, 73pp.

599 Cañadas A. and Hammond P. S. (2008). Abundance and habitat preferences of the short600 beaked common dolphin Delphinus delphis in the southwestern Mediterranean: implications 601 for conservation. Endangered Species Research 4:309-331.

602 Cañadas A. and Vázquez J.A. (2017). Common dolphins in the Alboran Sea: facing a 603 reduction in their suitable habitat due to an increase in Sea surface temperature. Deep-sea 604 Research. Part II, Topical Studies in Oceanography 141:306-318. 
605 Carrillo M., Pérez-Vallazza C.P. and Alvarez-Vázquez R. (2010). Cetacean diversity and 606 distribution off Tenerife (Canary Islands). Marine Biodiversity Records 3:1-9.

607 Correia A.M., Tepsich P., Rosso M., Caldeira R. and Sousa Pinto I. (2015). Cetacean 608 occurrence and spatial distribution: Habitat modeling for offshore waters in the Portuguese EEZ 609 (NE Atlantic). Journal of Marine Systems 143:73-85.

610 Davis R.W., Ortega-Ortiz J.G., Ribic C.A., Evans W.E., Biggs D.C., Ressler P.H., Cady 611 R.B., et al. (2002). Cetacean habitat in the northern oceanic Gulf of Mexico. Deep-Sea 612 Research Part I: Oceanographic Research Papers 49(1):121-142.

613 Development Core Team, R. (2012). $R$ : A Language and Environment for Statistical 614 Computing. R Foundation for Statistical Computing: Vienna Austria (ISNB: 3- 900051-07-0, 615 URL: http://www.R-project.org/).

616 Dinis A., R. Marques, L. Dias, D. Sousa, C. Gomes, N. Abreu, F. Alves (2017). Site Fidelity 617 of Blainville's Beaked Whale (Mesoplodon densirostris) off Madeira Island (Northeast 618 Atlantic). Aquatic Mammals 43(4): 387-390.

619 Dinis A., F. Alves, C. Nicolau, C. Ribeiro, M. Kaufmann, A. Cañadas, L. Freitas (2016). 620 Bottlenose dolphin Tursiops truncatus group dynamics, site fidelity, residency and movement 621 patterns in the Madeira Archipelago (North-East Atlantic). African Journal of Marine Science $62238: 151-160$.

623 Djiba A., Bamy I.L., Bilal A.S.O. and Van Waerebeek K. (2015). Biodiversity of cetaceans 624 in coastal waters of northwest Africa: new insights through platform-of-opportunity visual 625 surveying in 2011-2013. IOC Technical Series 115:283-297.

626 Elith J. and Leathwick J.R. (2009). Species Distribution Models: Ecological Explanation and 627 Prediction Across Space and Time. Annual Review of Ecology, Evolution, and Systematics $62840: 677-697$. 
ESRI (2016). ArcGIS Desktop: Release 10.5. Redlands, CA: Environmental Systems Research

630 Institute.

631 Fernandez M., Yesson C., Gannier A., Miller P.I. and Azevedo J.M.N. (2017). The

632 importance of temporal resolution for niche modelling in dynamic marine environments.

633 Journal of Biogeography 44:2816-2827.

634 Fernandez M., Yesson C., Gannier A., Miller P.I. and Azevedo J.M.N. (2018). A matter of

635 timing: how temporal scale selection influences cetacean ecological niche modelling. Marine 636 Ecology Progress Series 595:217-231.

637 Frederiksen M., Edwards M., Richardson A.J., Halliday N.C. and Wanless S. (2006). From 638 plankton to top predators: bottom-up control of a marine food web across four trophic levels. 639 Journal of Animal Ecology 75(6):1259-1268.

640

(2017).

Gridded

bathymetry

data.

641 http://www.gebco.net/data_and_products/gridded_bathymetry_data/ (accessed September 642 2017).

643 Goetz S., Read F.L., Ferreira M., Portela J.M., Santos M.B., Vingada J., Siebert U., et al. 644 (2015). Cetacean occurrence, habitat preferences and potential for cetacean - fishery 645 interactions in Iberian Atlantic waters: results from cooperative research involving local 646 stakeholders. Aquatic Conservation: Marine and Freshwater Ecosystems 25:138-154.

647 González L., Pierce G.J., Autret E., Torres-Palenzuela J.M. (2018). Multi-scale habitat 648 preference analyses for Azorean blue whales. PLoS ONE 13(9):e0201786.

649 Grémillet D., Lewis S., Drapeau L., Lingen C.D.V.D., Huggett J.A., Coetzee J.C., Verheye 650 H.M., et al. (2008). Spatial match-mismatch in the Benguela upwelling zone: should we expect 651 chlorophyll and sea-surface temperature to predict marine predator distributions? Journal of 652 Applied Ecology 45(2):610-621. 
Halicka Z. (2016). Temporal distribution of the short-beaked common dolphin (Delphinus

654 delphis) in the south of Madeira Island (Portugal) and relationship with oceanographic

655 variables. Msc thesis. Universidade do Algarve, Portugal.

\section{Hammond P.S., Macleod K., Berggren P., Borchers D.L., Burt L., Cañadas A., Desportes}

G., et al. (2013). Cetacean abundance and distribution in European Atlantic shelf waters to inform conservation and management. Biological Conservation 64:107-122.

Hazevoet C.J. and Frederick W. Wenzel F.W. (2000). Whales and dolphins (Mammalia, Cetacea) of the Cape Verde Islandso with special reference to the Humpback whale Megaptera novaeangliae (Borowski, 1781). Contributions to Zoology 69(3):197-211.

\section{Hazevoet C.J., Monteiro V., López P., Varo N., Torda G., Berrow S. and Gravanita B.} (2010). Recent data on whales and dolphins (Mammalia: Cetacea) from the Cape Verde Islands, including records of four taxa new to the archipelago. Zoologia Caboverdiana 1(2):75-99.

Jungblut S., Nachtsheim D.A., Boos K. and Joiris C.R. (2017). Biogeography of top predators - seabirds and marine mammals - along four latitudinal transects in the Atlantic Ocean. Deep Sea Research Part II: Topical Studies in Oceanography 141:59-3.

Kaschner K., Tittensor D.P., Ready J., Gerrodette T. and Worm B (2010). Current and Future Patterns of Global Marine Mammal Biodiversity. PLoS One 6(5):e19653.

Kaschner K., Quick N.J., Jewell R., Williams R. and Harris C.M. (2012). Global coverage of cetacean line-transect surveys: status quo, data gaps and future challenges. PLoS One 7(9):e44075.

Kiszka J., Macleod K., Van Canneyt O., Walker D. and Ridoux V. (2007). Distribution, encounter rates, and habitat characteristics of toothed cetaceans in the Bay of Biscay and adjacent waters from platform-of-opportunity data. ICES Journal of Marine Science 64:10331043. 

comparison of approaches for modelling the occurrence of marine animals. Hydrobiologia 612:21-32

Marçalo A., Nicolau L., Giménez J., Ferreira M., Santos J., Araújo H., Silva A., et al. (2018). Feeding ecology of the common dolphin (Delphinus delphis) in Western Iberian waters: 682 has the decline in sardine (Sardina pilchardus) affected dolphin diet? Marine Biology 165:44.

683 Marubini F., Gimona A., Evans P.G.H., Wright P.J. and Pierce G.J. (2009). Habitat 684 preferences and interannual variability in occurrence of the harbour porpoise Phocoena phocoena off northwest Scotland. Marine Ecology Progress Series 381:297-310.

Mason E. (2009). High-resolution Modelling of the Canary Basin Oceanic Circulation. PhD thesis. Universidad de Las Palmas de Gran Canaria, Las Palmas de Gran Canaria.

Meynier L., Pusineri C., Spitz J., Santos M.B., Pierce G.J. and Ridoux V. (2008). Intraspecific dietary variation in the short-beaked common dolphin Delphinus delphis in the Bay of Biscay: importance of fat fish. Marine Ecolology Progress Series 354:277-287.

Moura A.E., Sillero N. and Rodrigues A. (2012). Common dolphin (Delphinus delphis)

692 habitat preferences using data from two platforms of opportunity. Acta Oecologica 38:24-32.

693 NASA (2017). Ocean color data - MODISA. https://oceandata.sci.gsfc.nasa.gov/ (accessed 694 September 2017).

695 Pearce J.L. and Boyce M.S. (2006). Modelling distribution and abundance with presence only 696 data. Journal of Applied Ecology 43:405-412.

697 Peltier H., Authier M., Deaville R., Dabin W., Jepson P.D., van Canneyt O., Daniel P., et 698 al. (2016). Small cetacean bycatch as estimated from stranding schemes: the common dolphin 699 case in the northeast Atlantic. Environmental Science \& Policy 63:7-18.

700 Pierce G.J., Caldas M., Cedeira J., Santos M.B., Llavona A., Covelo P., Martínez G., et al. 701 (2010). Trends in cetacean sightings along the Galician coast, north-western Spain, 2003-2007, 
and inferences about cetacean habitat preferences. Journal of the Marine Biological Association

703 of the United Kingdom 90 (8): 1547-1560.

704 Piroddi C., Bearzi G., Gonzalvo J. and Christensen V. (2011). From common to rare: the

705 case of the Mediterranean common dolphin. Biological Conservation 144:2490-2498.

706 Pirotta E., Matthiopoulos J., MacKenzie M., Scott-Hayward L. and Rendell L. (2011).

707 Modelling sperm whale habitat preference: a novel approach combining transect and follow 708 data. Marine Ecology Progress Series 436:257-272.

709 Quian S.S. (2009). Environmental and Ecological Statistics with R. Chapman \& Hall: Canada.

Redfern J.V., Ferguson M.C., Becker E.A., Hyrenbach K.D., Good C., Barlow J., Kaschne

K., et al. (2006). Techniques for cetacean-habitat modeling. Marine Ecology Progress Series

$712 \quad 310: 271-295$.

713 Roberts J.J., Best B.D., Dunn D.C., Treml E.A. and Halpin P.N. (2010). Marine Geospatial

714 Ecology Tools: An integrated framework for ecological geoprocessing with ArcGIS, Python,

715 R, MATLAB, and C++. Environmental Modelling \& Software 25:1197-1207.

716 Robinson I.S. (2010). Discovering the Ocean from Space - The Unique Applications of

717 Satellite Oceanography. Springer: Bath, UK.

718 Sala I., Caldeira R.M.A., Estrada-Allis S.N., Froufe E. and Couvelard X. (2013).

719 Lagrangian transport pathways in the northeast Atlantic and their environmental impact.

720 Limnology \& Oceanography: Fluids \& Environments 3:40-60.

721 Santos M.B., German I., Correia D., Read F. L., Cedeira J.M., Caldas M., López A., et al.

722 (2013). Long-term variation in common dolphin diet in relation to prey abundance. Marine

723 Ecology Progress Series 481:249-268.

724 Santos M.B., Saavedra C. and Pierce G.J. (2014). Quantifying the predation on sardine and

725 hake by cetaceans in the Atlantic waters of the Iberian Peninsula. Deep-sea research. Part II,

726 Topical studies in oceanography 106:232-244. 
727 Santos M.B. and Pierce G.J. (2015). Marine mammals and good environmental status:

728 science, policy and society; challenges and opportunities. Hydrobiologia 750:13-41.

729 Schlacher T.A., Rowden, A.A., Dower J.D. and Consalvey M. (2010). Seamount science 730 scales undersea mountains: new research and outlook. Marine Ecology 31:1-13.

731 Silva M.A., Prieto R., Cascão I., Seabra M.I., Machete M., Baumgartner M.F. and Santos

732 R.S. (2014). Spatial and temporal distribution of cetaceans in the mid-Atlantic waters around 733 the Azores. Marine Biology Research 10:123-137.

734 Smith J.M., Pierce G.J., Zuur A.F., Martins H., Martins M.C., Porteiro F. and Rocha F. 735 (2011). Patterns of investment in reproductive and somatic tissues in the loliginid squid Loligo 736 forbesii and Loligo vulgaris in Iberian and Azorean waters. Hydrobiologia 670:201-221.

737 Spyrakos E., Santos-Diniz T.C., Martinez-Iglesias G., Torres-Palenzuela J.M. and Pierce

738 G.J. (2011). Spatio temporal patterns of marine mammal distribution in coastal waters of 739 Galicia, NW Spain. Hydrobiologia 670:87-109.

740 Stockin K.A., Pierce G.J., Binedell V., Wiseman N. and Orams M.B. (2008). Factors 741 Affecting the Occurrence and Demographics of Common Dolphins (Delphinus sp.) in the 742 Hauraki Gulf, New Zealand. Aquatic Mammals 34(2):200-211.

743 Tobeña M., Prieto R., Machete M. and Silva M.A. (2016). Modeling the Potential 744 Distribution and Richness of Cetaceans in the Azores from Fisheries Observer Program Data. $745 \quad$ Frontiers in Marine Science 3:202.

746 Viddi F.A., Hucke-Gaete R., Torres-Florez J.P. and Ribeiro S. (2010). Spatial and seasonal 747 variability in cetacean distribution in the fjords of northern Patagonia, Chile. ICES Journal of $748 \quad$ Marine Science 67:959-970.

749 Weir C.R. (2010) A review of cetacean occurrence in West African waters from the Gulf of 750 Guinea to Angola. Mammal Review 40(1):2-39. 
Weir C.R. and Pierce G.J. (2013) A review of the human activities impacting cetaceans in the

752 eastern tropical Atlantic. Mammal Review 43:258-274.

753

754

755

\section{Weir C.R., Coles P., Ferguson A., May D., Baines M., Figueirdo I., Reichelt M., et al.} (2014) Clymene dolphins (Stenella clymene) in the eastern tropical Atlantic: distribution, group size, and pigmentation pattern. Journal of Mammalogy 95(6):1289-1298.

Zuur A.F., Ieno E. and Elphick C. (2010). A protocol for data exploration to avoid common statistical problems. Methods in Ecology and Evolution 1:3-14.

\section{FIGURE LEGENDS}

Fig. 1. The study area within the Eastern North Atlantic, with surveyed transects and visited ports.

Fig. 2. Spatial distribution of common dolphin (Delphinus delphis) occurrences with survey effort transects represented in grey lines. Only sightings on effort are represented.

Fig. 3. Temporal variation of common dolphin (Delphinus delphis) occurrence, encounter rate and monthly survey effort in nautical miles (nmi). Data from the entire study area, within the Eastern North Atlantic, is summarized. Only sightings on effort are considered.

Fig. 4. GAM predicted splines of the response variable dolphin presence as a function of the explanatory variables for the observation effects model produced for common dolphin (Delphinus delphis). The degrees of freedom are in brackets on the y-axis. Tick marks above the $\mathrm{x}$-axis indicate the distribution of observations. Dashed lines delimit the $95 \%$ confidence intervals of the spline functions and dots on the graph area represent the residuals. For parameters abbreviations, see table 2 .

Fig. 5. GAM predicted perspective graphs of the response variable dolphin presence as a function of the explanatory variables for the spatiotemporal model produced for common dolphin (Delphinus delphis). These correspond to variables introduced as interactions in the model, spatially (latitude $x$ longitude) and temporally (day of the year $x$ year), and represent in a surface the variation along the two variables. The degrees of freedom are in brackets on the z-axis. Grey surfaces define the upper and lower limits of the $95 \%$ confidence interval. For parameters abbreviations, see table 2 .

Fig. 6. GAM predicted splines of the response variable dolphin presence as a function of the explanatory variables for the environmental model produced for common dolphin (Delphinus delphis). The degrees of freedom are in brackets on the y-axis. Tick marks above the $\mathrm{x}$-axis indicate the distribution of observations. Dashed lines delimit the $95 \%$ confidence intervals of the spline functions and dots on the graph area represent the residuals. resid_dist_coast residuals from the model for distance to coast with depth as predictor. For other parameters abbreviations, see table 2 . 
787 Fig. 7. GAM predicted splines of the response variable dolphin presence as a function of the 788 explanatory variables for the final model produced for common dolphin (Delphinus delphis). 789 The degrees of freedom for non-linear fits are in brackets on the y-axis. Tick marks above the $790 \mathrm{x}$-axis indicate the distribution of observations. Dashed lines delimit the $95 \%$ confidence 791 intervals of the spline functions and dots on the graph area represent the residuals. Perspective 792 graphs correspond to variables introduced as interactions in the model, spatially (latitude $\mathrm{x}$ 793 longitude) and temporally (day of the year $x$ year), and represent in a surface the variation along 794 the two variables. In these graphs, the degrees of freedom are in brackets on the z-axis and grey 795 surfaces define the upper and lower limits of the $95 \%$ confidence interval. For parameters 796 abbreviations, see table 2.

797 Fig. 8. GAM predicted probabilities of common dolphin (Delphinus delphis) for the set of the 798 response variable points. 
800 Table 1. Survey effort, sightings of common dolphin (Delphinus delphis), group size and total 801 encounter rates, for each sampled route and season of survey. A trip is considered a round-trip 802 starting and ending in Mainland Portugal while a survey is a leg between two ports. Survey 803 effort is presented in nautical miles (nmi) rounded to the unit. For the group size, the minimum 804 (min), maximum ( $\max$ ), mean and standard deviation (std) values presented are based on the 805 best estimate of the number of animals per sighting on effort, accessed by the observer

\begin{tabular}{|c|c|c|c|c|c|c|c|}
\hline Route & Year & Season & $\begin{array}{c}\mathrm{Nr} \text { of trips / } \mathrm{Nr} \\
\text { of surveys }\end{array}$ & $\begin{array}{c}\text { Survey } \\
\text { effort }\end{array}$ & $\begin{array}{c}\text { Total sightings / } \\
\text { Sightings on effort }\end{array}$ & $\begin{array}{c}\text { Group size } \\
\min -\max (\operatorname{mean} \pm \mathbf{s t d})\end{array}$ & ER \\
\hline \multirow{5}{*}{ Madeira } & 2012 & July-October & $9 / 19$ & 5025 & $17 / 14$ & $1-40(12.21 \pm 10.19)$ & 0.28 \\
\hline & 2013 & July-October & $13 / 29$ & 5616 & $30 / 22$ & $1-120(15.91 \pm 29.16)$ & 0.39 \\
\hline & 2014 & August-October & $11 / 23$ & 3938 & $22 / 16$ & $2-100(18.31 \pm 24.54)$ & 0.41 \\
\hline & 2015 & July-October & $18 / 44$ & 6009 & $30 / 21$ & $1-80(20.95 \pm 19.29)$ & 0.35 \\
\hline & 2016 & July-October & $16 / 46$ & 4887 & $28 / 19$ & $2-100(12.95 \pm 22.62)$ & 0.39 \\
\hline \multirow{3}{*}{ Azores } & 2014 & July-September & $6 / 32$ & 5556 & $30 / 19$ & $2-40(8.16 \pm 9.50)$ & 0.34 \\
\hline & 2015 & July-October & $7 / 33$ & 3444 & $37 / 14$ & $3-80(21.86 \pm 20.53)$ & 0.41 \\
\hline & 2016 & July-October & $7 / 31$ & 3920 & $26 / 21$ & $1-50(16.48 \pm 15.77)$ & 0.54 \\
\hline Cape & 2015 & May-October & $7 / 46$ & 8723 & $29 / 24$ & $3-2500(168.29 \pm 510.22)$ & 0.28 \\
\hline Verde & 2016 & February/ August-December & $5 / 42$ & 6203 & $34 / 22$ & $2-40(13.32 \pm 10.58)$ & 0.35 \\
\hline \multicolumn{3}{|r|}{ TOTAL } & $99 / 345$ & 53321 & $283 / 192$ & $1-2500(34.58 \pm 185.04)$ & 0.36 \\
\hline
\end{tabular}


807 Table 2. Variables tested as predictors for statistical modelling and its characteristics.

\begin{tabular}{|c|c|c|c|c|c|c|c|c|}
\hline Model & Variables & Source & Reference & Product name & $\begin{array}{l}\text { Name used in } \\
\text { the analysis }\end{array}$ & $\begin{array}{c}\text { Spatial } \\
\text { resolution }\end{array}$ & $\begin{array}{l}\text { Temporal } \\
\text { resolution }\end{array}$ & Unit \\
\hline \multirow{3}{*}{$\begin{array}{c}\text { Observation } \\
\text { effects }\end{array}$} & Sea-state & Sea-surveys & - & - & sea_state & - & - & Douglas scale \\
\hline & Wind-state & Sea-surveys & - & - & wind_state & - & - & Beaufort scale \\
\hline & Visibility & Sea-surveys & - & - & visibility & - & - & $1-10$ scale $^{\mathrm{a}}$ \\
\hline \multirow{4}{*}{ Spatiotemporal } & Latitude & $\begin{array}{c}\begin{array}{c}\text { Sea-surveys } \\
\text { (GPS) }\end{array} \\
\text { (G) }\end{array}$ & - & - & lat & - & $\sim 10$ seconds & Decimal degrees \\
\hline & Longitude & $\begin{array}{l}\text { Sea-surveys } \\
\quad(\text { GPS })\end{array}$ & - & - & lon & - & $\sim 10$ seconds & Decimal degrees \\
\hline & Day of the year & Date of survey & - & - & day & - & Daily & Day \\
\hline & Year & $\begin{array}{l}\text { Year of } \\
\text { survey }\end{array}$ & - & - & year & - & Yearly & Year \\
\hline \multirow{11}{*}{ Environmental } & Depth & GEBCO & GEBCO, 2017 & bathy_30arc_second & depth & $30 \mathrm{sec}$ & - & Meters (m) \\
\hline & Slope & GEBCO & GEBCO, 2017 & - & slope & $30 \mathrm{sec}$ & - & Degrees $\left({ }^{\circ}\right)$ \\
\hline & $\begin{array}{l}\text { Distance to } \\
\text { coast }\end{array}$ & - & - & - & dist_coast & - & - & Kilometres $(\mathrm{km})$ \\
\hline & $\begin{array}{l}\text { Distance to } \\
\text { seamounts }\end{array}$ & GEBCO & GEBCO, 2017 & - & dist_sm & - & - & Kilometres $(\mathrm{km})$ \\
\hline & Chlorophyll & MODIS Aqua & NASA, 2017 & CHL_chlor_a & CHL & $4 \mathrm{~km} / 9 \mathrm{~km}$ & $\begin{array}{l}8 \text { day / } \\
\text { monthly }\end{array}$ & Density $\left(\mathrm{mg} \mathrm{m}^{-3}\right)$ \\
\hline & $\begin{array}{c}\text { Chlorophyll lag } \\
1 \text { week }\end{array}$ & MODIS Aqua & NASA, 2017 & CHL_chlor_a & CHL_lag1w & $4 \mathrm{~km} / 9 \mathrm{~km}$ & $\begin{array}{l}8 \text { day / } \\
\text { monthly }\end{array}$ & Density $\left(\mathrm{mg} \mathrm{m}^{-3}\right)$ \\
\hline & $\begin{array}{l}\text { Chlorophyll lag } \\
2 \text { weeks }\end{array}$ & MODIS Aqua & NASA, 2017 & CHL_chlor_a & CHL_lag2w & $4 \mathrm{~km} / 9 \mathrm{~km}$ & $\begin{array}{l}8 \text { day / } \\
\text { monthly }\end{array}$ & Density $\left(\mathrm{mg} \mathrm{m}^{-3}\right)$ \\
\hline & $\begin{array}{l}\text { Chlorophyll lag } \\
1 \text { month }\end{array}$ & MODIS Aqua & NASA, 2017 & CHL_chlor_a & CHL_lag1m & $4 \mathrm{~km} / 9 \mathrm{~km}$ & $\begin{array}{l}8 \text { day / } \\
\text { monthly }\end{array}$ & Density $\left(\mathrm{mg} \mathrm{m}^{-3}\right)$ \\
\hline & $\begin{array}{l}\text { Chlorophyll lag } \\
2 \text { months }\end{array}$ & MODIS Aqua & NASA, 2017 & CHL_chlor_a & CHL_lag2m & $4 \mathrm{~km} / 9 \mathrm{~km}$ & $\begin{array}{l}8 \text { day / } \\
\text { monthly }\end{array}$ & Density $\left(\mathrm{mg} \mathrm{m}^{-3}\right)$ \\
\hline & $\begin{array}{l}\text { Sea-surface } \\
\text { temperature }\end{array}$ & MODIS Aqua & NASA, 2017 & sst4_4_sst4 & SST & $4 \mathrm{~km} / 9 \mathrm{~km}$ & $\begin{array}{l}8 \text { day / } \\
\text { monthly }\end{array}$ & Celsius $\left({ }^{\circ} \mathrm{C}\right)$ \\
\hline & $\begin{array}{l}\text { Mean sea level } \\
\text { anomalies }\end{array}$ & AVISO & AVISO, 2017 & $\begin{array}{l}\text { MSLA_h_DT_all_sat_merged_0.25/ } \\
\text { MSLA_h_NRT_al_sat_merged_0.25 }\end{array}$ & MSLA & 0.25 degree & $\begin{array}{l}8 \text { day / } \\
\text { monthly }\end{array}$ & Centimetres $(\mathrm{cm})$ \\
\hline Final & \multicolumn{8}{|c|}{ All variables above } \\
\hline
\end{tabular}


Table 3. Best GAM model results for common dolphin (Delphinus delphis).

\begin{tabular}{|c|c|c|c|c|c|c|c|c|c|c|}
\hline $\begin{array}{c}\text { Model } \\
\text { Parameters }\end{array}$ & Estimate & edf & se & z-value & Chi-square & p-value & $\begin{array}{l}\text { Deviance } \\
\text { explained } \\
\quad(\%)\end{array}$ & $\mathbf{r}^{2}$ & UBRE & $\begin{array}{c}\text { AUC } \\
(\text { CI 95\%) }\end{array}$ \\
\hline \multicolumn{11}{|l|}{ Observation effects } \\
\hline Intercept & -4.18 & & 0.06 & -68.32 & & $<0.001$ & & & & \\
\hline \multicolumn{11}{|l|}{$\underline{\text { Smoother terms }}$} \\
\hline sea_state & & 1.61 & & & 26.34 & $<0.001$ & & & & \\
\hline wind_state & & 2.92 & & & 135.44 & $<0.001$ & & & & \\
\hline visibility & & 2.88 & & & 11.62 & 0.008 & & & & \\
\hline \multicolumn{7}{|c|}{$\begin{array}{c}\text { Best model (n=20388; } 192 \text { presences): } \\
C D \sim S(\text { sea_state })+s(\text { wind_state })+s(\text { visibility })\end{array}$} & 4.11 & $9.41^{\mathrm{E}-3}$ & -0.82 & $\begin{array}{c}0.689 \\
(0.619- \\
0.758) \\
\end{array}$ \\
\hline $\begin{array}{c}\text { Spatiotemporal } \\
\text { Intercept }\end{array}$ & -4.83 & & 0.10 & -49.82 & & $<0.001$ & & & & \\
\hline lat, lon & & 14.65 & & & 464.95 & $<0.001$ & & & & \\
\hline \multirow[t]{2}{*}{ day,year } & & 12.33 & & & 81.95 & $<0.001$ & & & & \\
\hline & \multicolumn{5}{|c|}{$\begin{array}{l}\text { Best model (n=20388; } 192 \text { presences }): \\
\quad C D \sim s(\text { lat,lon })+s(\text { day,year })\end{array}$} & & 16.5 & 0.06 & -0.84 & $\begin{array}{l}0.809 \\
(0.727- \\
0.891) \\
\end{array}$ \\
\hline $\begin{array}{l}\text { Environmental } \\
\text { Intercept } \\
\text { Smoother terms }\end{array}$ & -4.81 & & 0.21 & -22.52 & & $<0.001$ & & & & \\
\hline depth & & 1.84 & & & 160.32 & $<0.001$ & & & & \\
\hline resid_dist_coast & & 2.75 & & & 21.34 & $<0.001$ & & & & \\
\hline slope & & 2.87 & & & 9.69 & 0.017 & & & & \\
\hline dist_sm & & 2.80 & & & 18.27 & $<0.001$ & & & & \\
\hline CHL_9km_monthly & & 2.58 & & & 19.12 & 0.005 & & & & \\
\hline SST_4km_8day & & 2.83 & & & 22.42 & $<0.001$ & & & & \\
\hline MS̄LA_Eday & & 2.83 & & & 9.83 & 0.015 & & & & \\
\hline \multicolumn{7}{|c|}{$\begin{array}{c}\mathrm{CD} \sim \text { resid_dist_coast }+\mathrm{s}(\text { depth })+\mathrm{s}(\text { slope })+\mathrm{s}(\text { dist_sm })+ \\
\mathrm{s}(\mathrm{SST} 4 \mathrm{~km} \text { 8day })+\mathrm{s}(\mathrm{CHL} \text { 9 } \mathrm{km} \text { _monthly })+\mathrm{s}(\text { MSLA_8day })\end{array}$} & 15.5 & 0.05 & -0.84 & $\begin{array}{c}0.744 \\
(0.651- \\
0.838) \\
\end{array}$ \\
\hline \multicolumn{11}{|c|}{ " } \\
\hline Intercept & -4.73 & & 0.10 & -49.89 & & $<0.001$ & & & & \\
\hline \multicolumn{11}{|l|}{ Smoother terms } \\
\hline wind_state & & 2.87 & & & 45.16 & $<0.001$ & & & & \\
\hline visibility & & 2.93 & & & 17.98 & $<0.001$ & & & & \\
\hline lat,lon & & 14.39 & & & 104.02 & $<0.001$ & & & & \\
\hline day,year & & 11.03 & & & 66.88 & $<0.001$ & & & & \\
\hline depth & & 1.04 & & & 26.54 & $<0.001$ & & & & \\
\hline dist_sm & & 2.84 & & & 16.17 & 0.001 & & & & \\
\hline MSLA_8day & & 2.97 & & & 28.66 & $<0.001$ & & & & \\
\hline \multicolumn{7}{|c|}{$\begin{array}{c}\text { Best model }(\mathbf{n}=\mathbf{1 9 6 5 8} ; \mathbf{1 8 9} \text { presences }): \\
\mathrm{CD} \sim \mathrm{CHL} \text { _9km_monthly }+\mathrm{s}(\text { wind_state })+\mathrm{s}(\text { visibility })+\mathrm{s}(\text { lat,lon })+\mathrm{s}(\text { day,year })+ \\
\mathrm{s}(\text { depth })+\mathrm{s}(\text { dist_sm })+\mathrm{s}(\text { MSLA_8day })\end{array}$} & 22.3 & 0.09 & -0.85 & $\begin{array}{l}0.727 \\
(0.639- \\
0.814)\end{array}$ \\
\hline
\end{tabular}




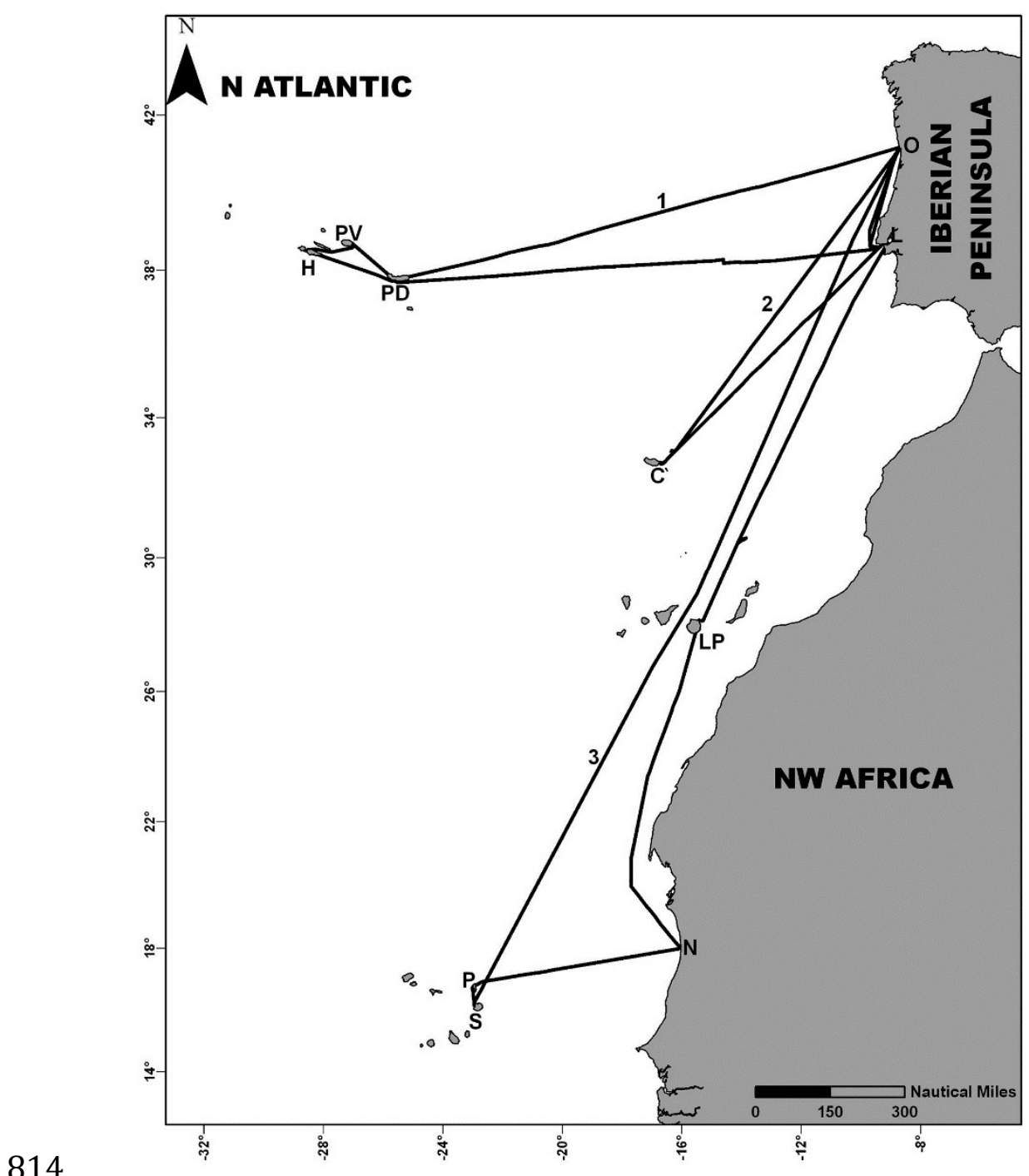

Routes:

1 - Azores

2 - Madeira

3 - Cape Verde

Most visited ports:

O - Oporto, Mainland Portugal L - Lisbon, Mainland Portugal PD - Ponta Delgada, Azores $\mathrm{H}$ - Horta, Azores

PV - Praia da Vitória, Azores

C - Caniçal, Madeira

LP - Las Palmas, Canaries

$\mathrm{N}$ - Nouakchott, Mauritania

P - Palmeira, Cape Verde

S - Sal Rei, Cape Verde

\section{Other ports}

(visited 3 times or less):

- Ferrol, Mainland Spain

- Nouadhibou, Mauritania

- Praia, Cape Verde

- Mindelo, Cape Verde

- Dakar, Senegal

\section{$815 \quad$ Figure 1}




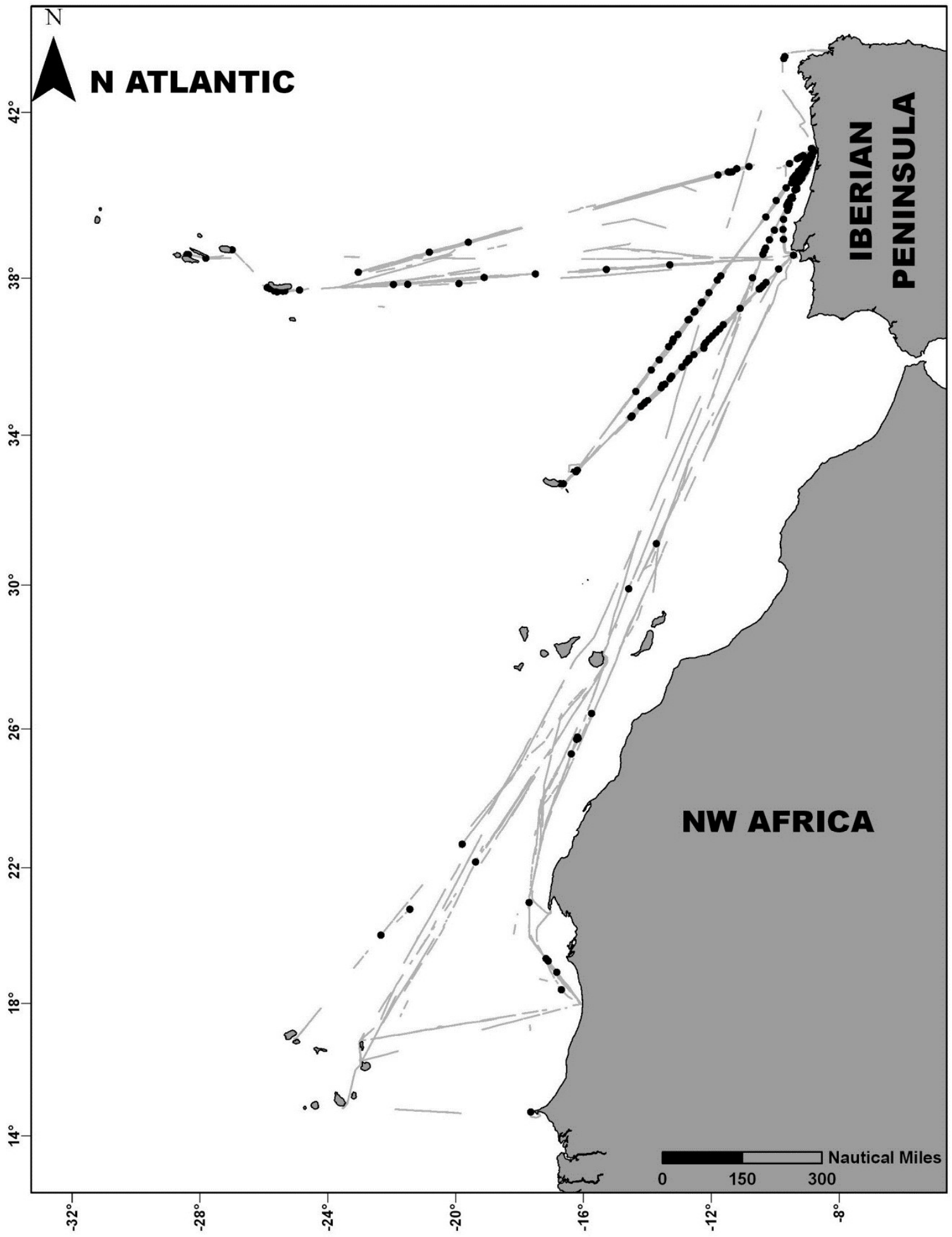

816

817 Figure 2 


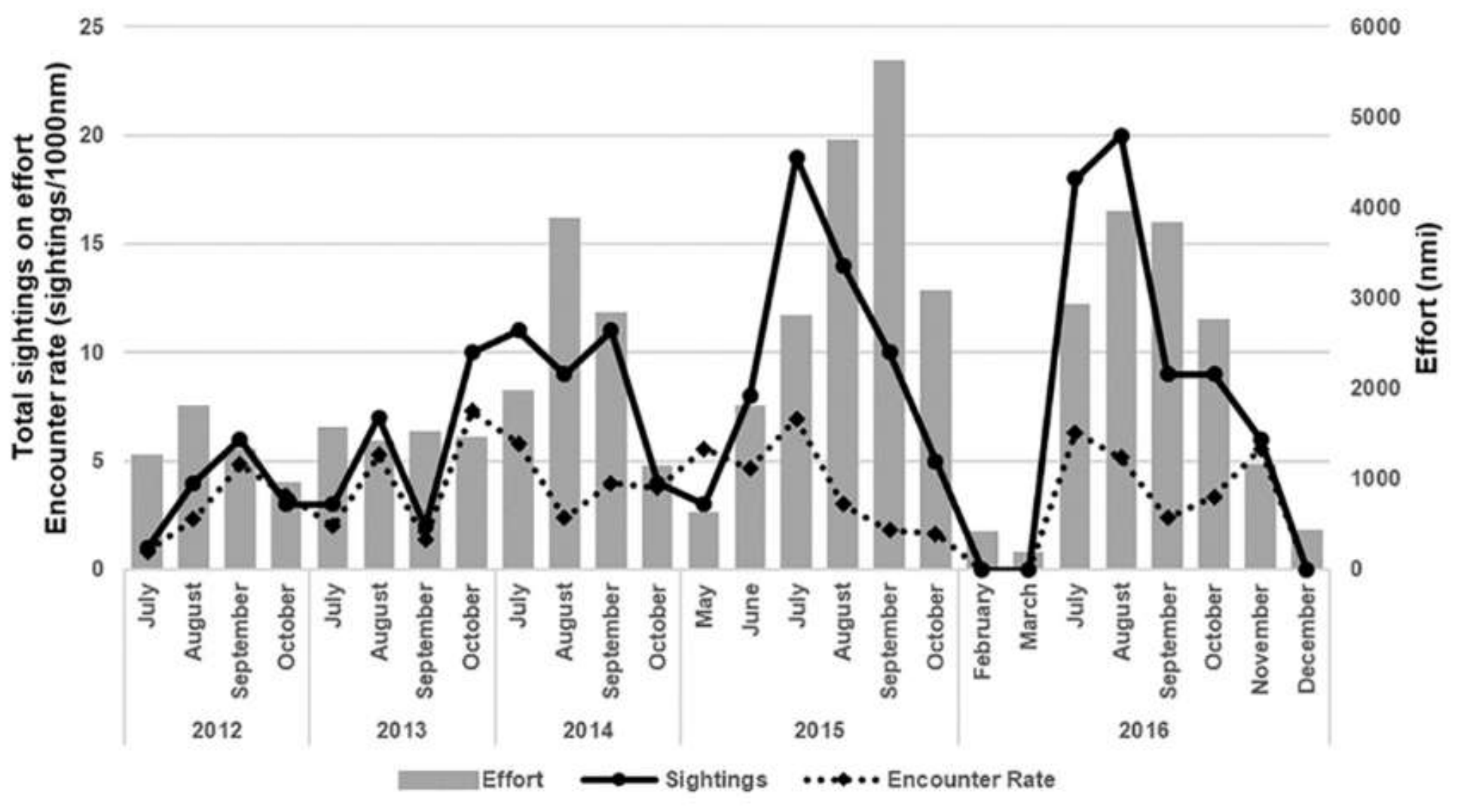

Figure 3 

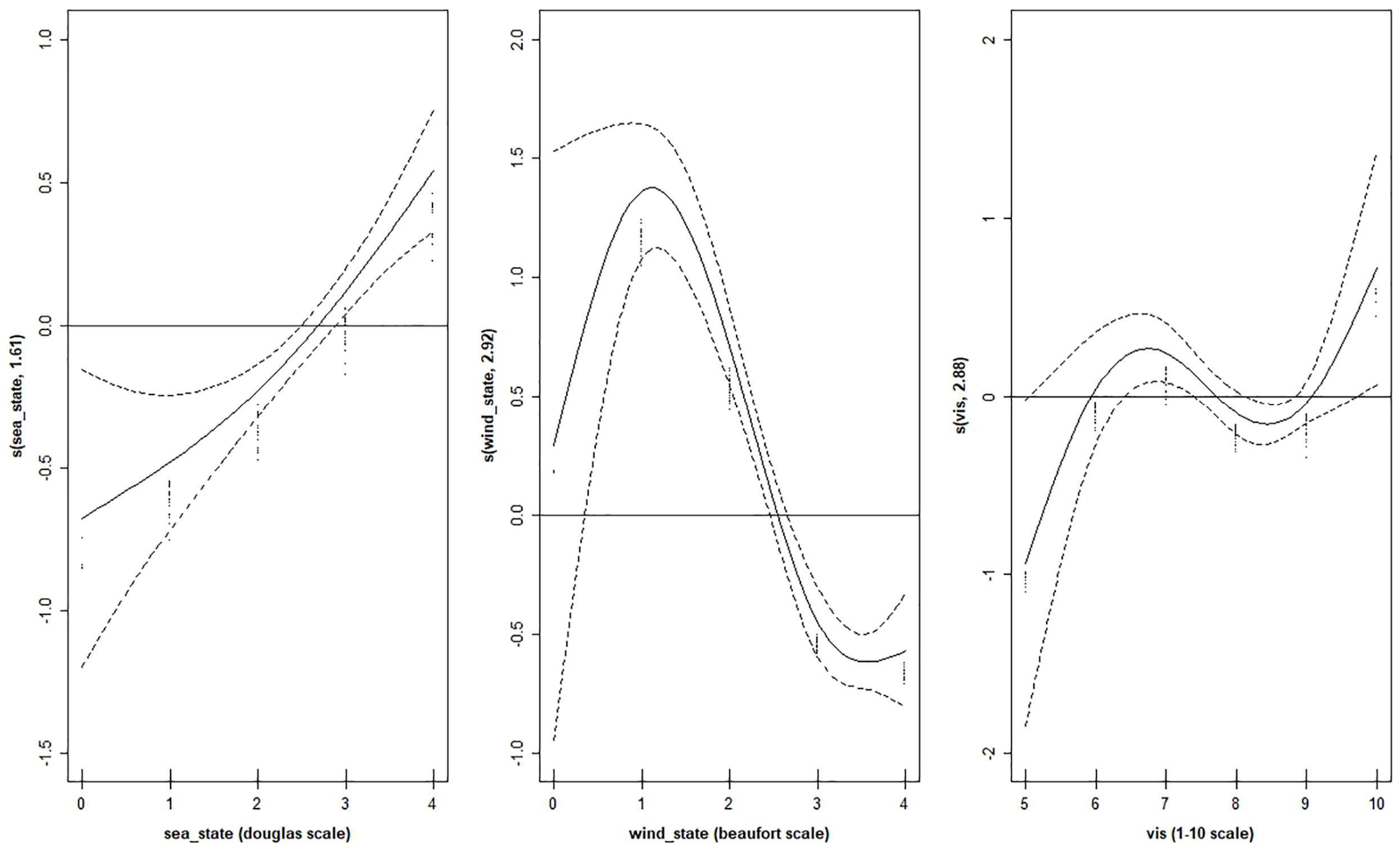

Figure 4 


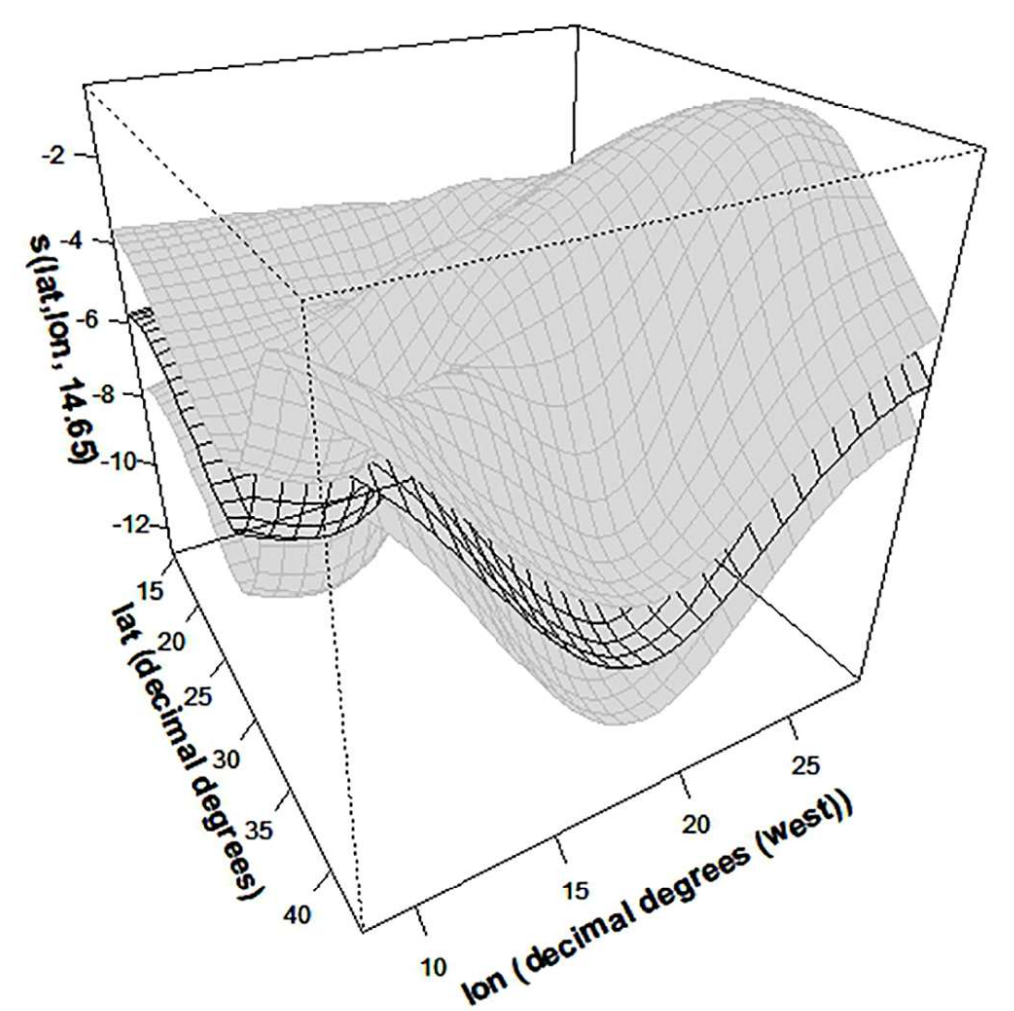

822

823
Figure 5

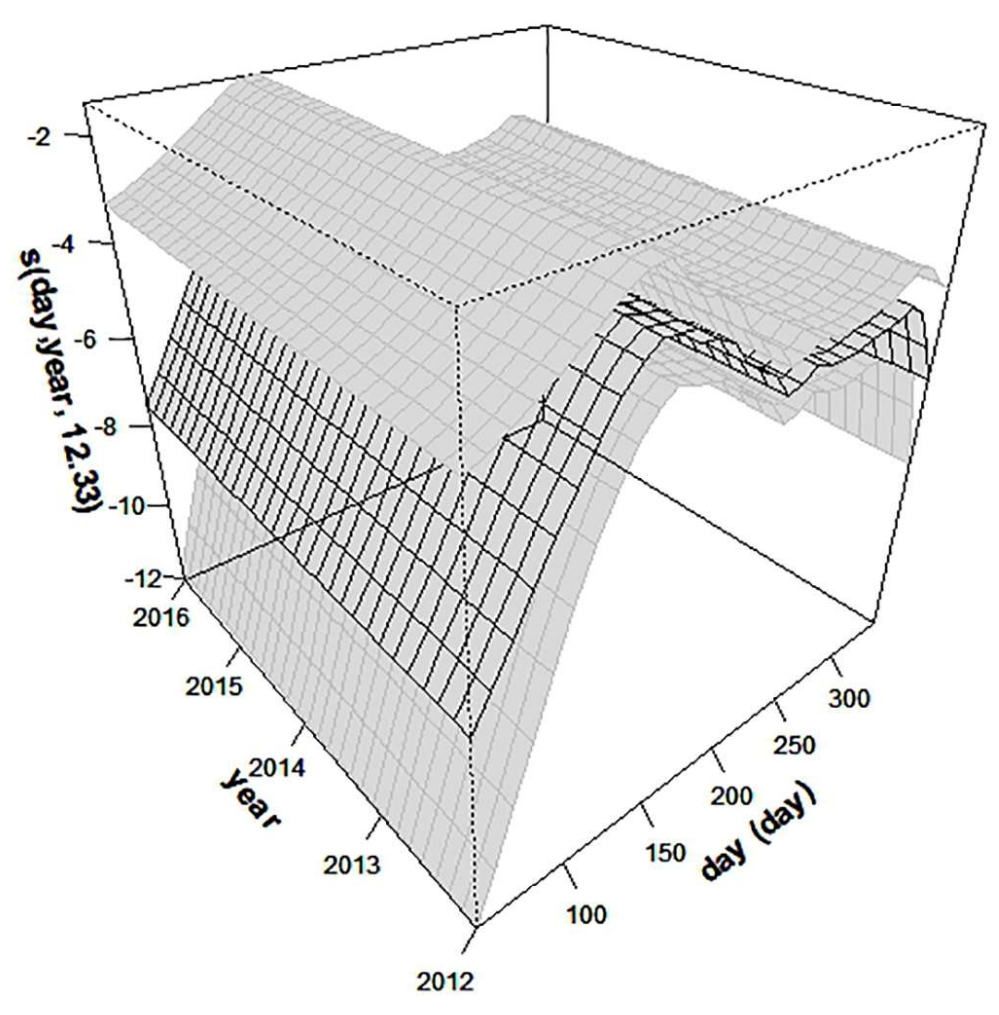

grey are +/- 1.96 s.e. 

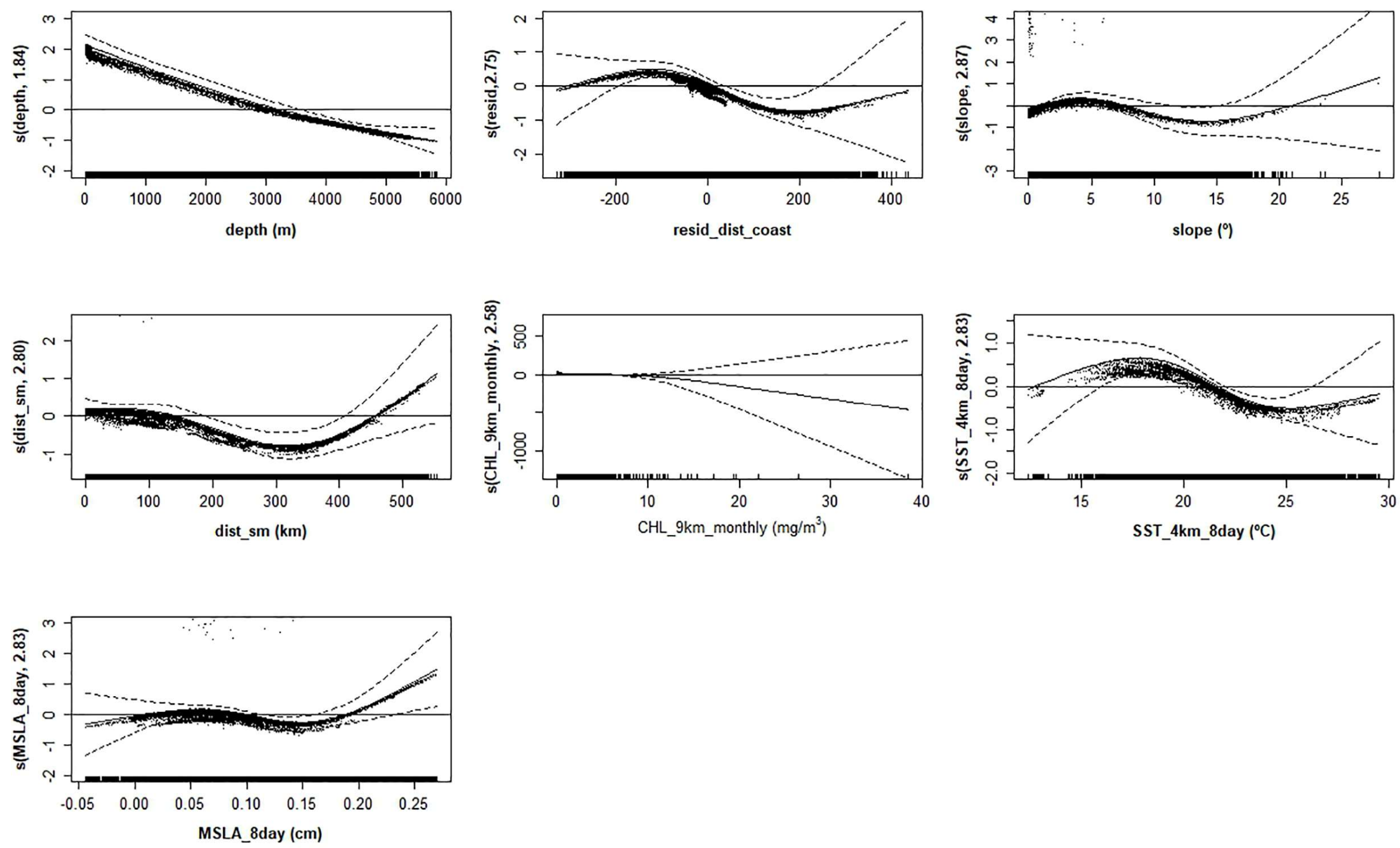

Figure 6 

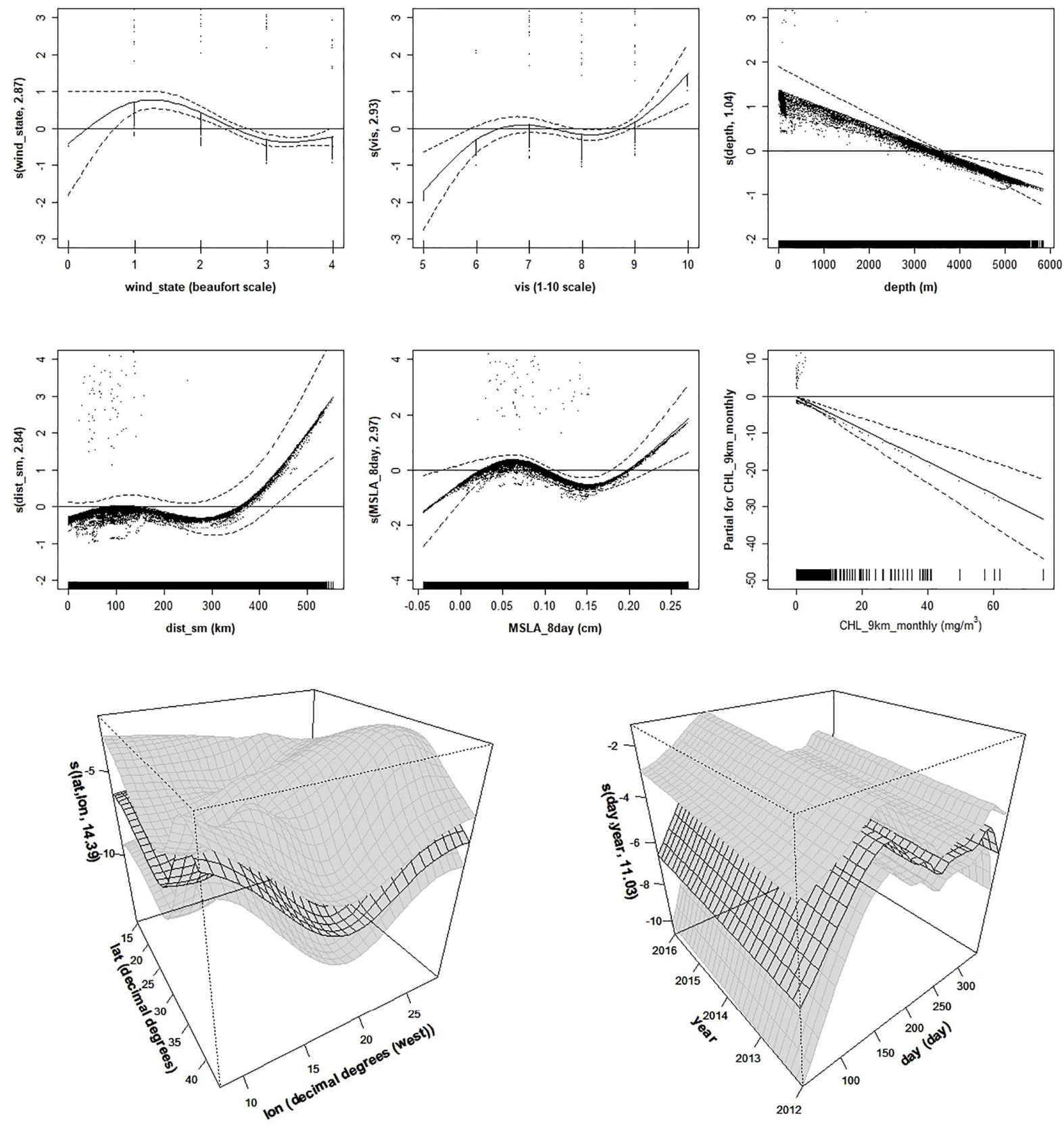

826

grey are $+/-1.96$ s.e.

grey are $+/-1.96$ s.e.

827 Figure 7 


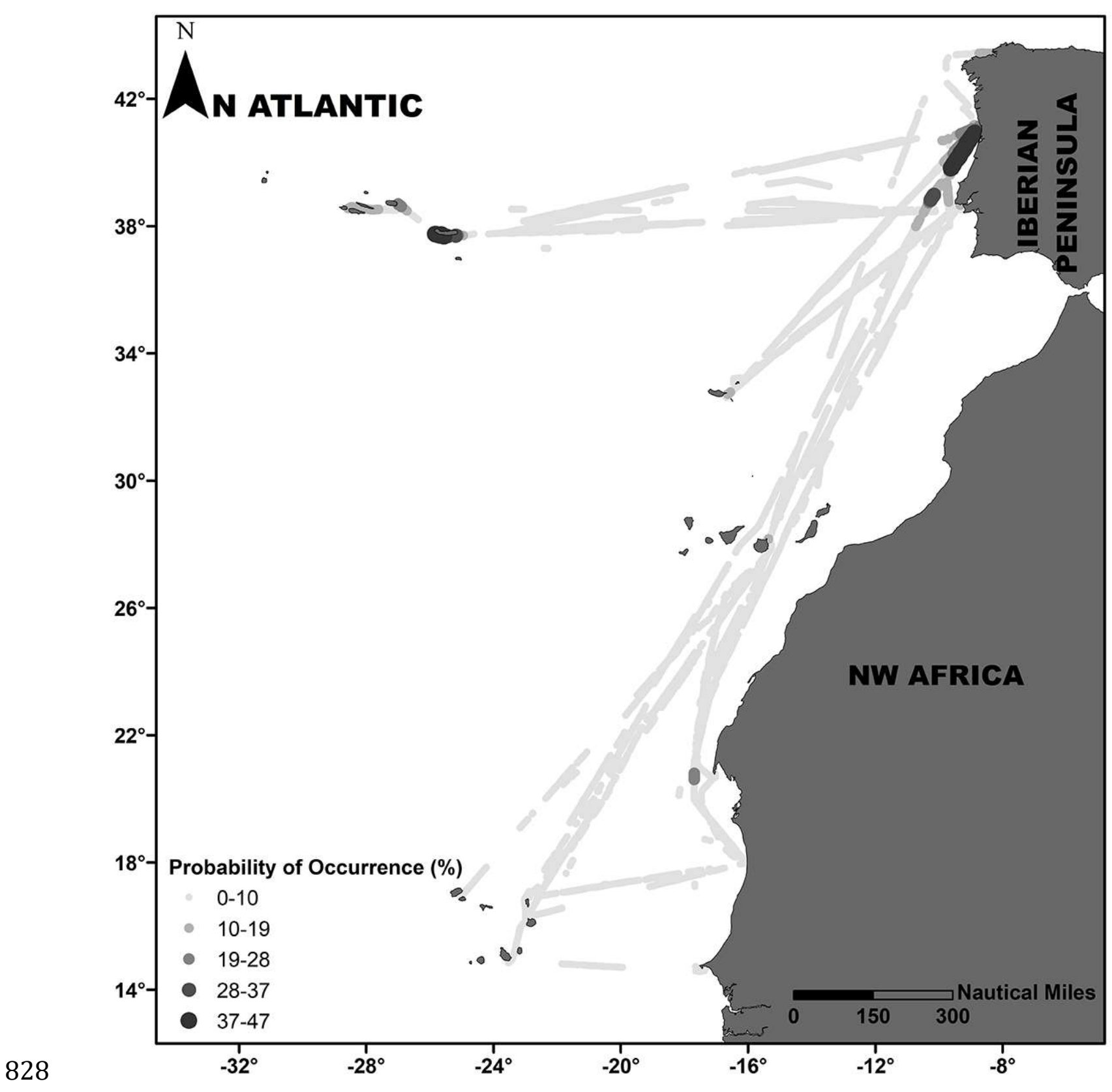

$829 \quad$ Figure 8 